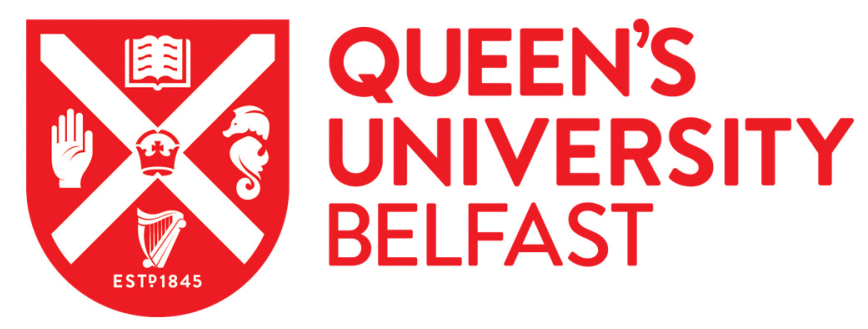

\title{
Antisepsis of the skin before spinal surgery with povidone iodine- alcohol followed by chlorhexidine gluconate-alcohol versus povidone iodine-alcohol applied twice for the prevention of contamination of the wound by bacteria: a randomised controlled trial
}

Patrick, S., McDowell, A., Lee, A., Frau, A., Martin, U., Gardner, E., McLorinan, G. C., \& Eames, N. (2017). Antisepsis of the skin before spinal surgery with povidone iodine-alcohol followed by chlorhexidine gluconatealcohol versus povidone iodine-alcohol applied twice for the prevention of contamination of the wound by bacteria: a randomised controlled trial. The Bone and Joint Journal , 99(B), 1354-1365.

https://doi.org/10.1302/0301-620X.99B10.BJJ-2017-0291.R1

Published in:

The Bone and Joint Journal

Document Version:

Peer reviewed version

Queen's University Belfast - Research Portal:

Link to publication record in Queen's University Belfast Research Portal

Publisher rights

Copyright 2017 British Editorial Society of Bone and Joint Surgery.

This work is made available online in accordance with the publisher's policies. Please refer to any applicable terms of use of the publisher.

\section{General rights}

Copyright for the publications made accessible via the Queen's University Belfast Research Portal is retained by the author(s) and / or other copyright owners and it is a condition of accessing these publications that users recognise and abide by the legal requirements associated with these rights.

Take down policy

The Research Portal is Queen's institutional repository that provides access to Queen's research output. Every effort has been made to ensure that content in the Research Portal does not infringe any person's rights, or applicable UK laws. If you discover content in the

Research Portal that you believe breaches copyright or violates any law, please contact openaccess@qub.ac.uk. 
Pre-spinal surgery skin antisepsis with povidone iodine-alcohol followed by chlorhexidine gluconate-alcohol versus povidone iodine-alcohol applied twice for prevention of surgical wound contamination by bacteria: a randomised, controlled trial.

S Patrick, A McDowell, A Lee, A Frau, U Martin, E Gardner, G McLorinan, N Eames S Patrick, BSc, PhD, DSc. Chair of Molecular Medical Bacteriology A McDowell, BSc, PhD. Senior Post-doctoral Research Fellow A Lee, BSc, PhD. Post-doctoral Research Fellow A Frau, BSc, PhD. Post-doctoral Research Fellow, Centre for Experimental Medicine, School of Medicine Dentistry and Biomedical Sciences, Queen's University of Belfast, 97 Lisburn Road, Belfast, BT9 7BL, UK .

N Eames, MD, FRCS. Consultant Spinal Surgeon Regional Lead Clinician Spinal Surgery Northern Ireland

G McLorinan, MD, FRCS. Consultant Spinal Surgeon

U Martin, Nursing Diploma. Research Nurse.

Regional Trauma and Orthopaedic Service, Royal Victoria and Musgrave Park Hospitals, Belfast Health and Social Care Trust, Belfast, UK.

E Gardner, MSc. Head of Statistics,

Northern Ireland Clinical Trials Unit, The Royal Hospitals, Belfast, UK

Correspondence to: S Patrick; email: s.patrick@qub.ac.uk 


\section{Author Contribution}

S Patrick: Principal Investigator, Study concept, Obtained funding, Study design and execution, Data collection and analysis, Statistical analysis, Data interpretation, Wrote the paper.

A McDowell: Contribution to laboratory protocol design, Data collection and analysis, Commented on paper.

A Lee: Contribution to laboratory protocol design, Recruited patients, Organised disinfectant allocation, Sample collection, Data collection and analysis, Commented on paper.

A Frau: Contribution to laboratory protocol design, Data collection and analysis, Commented on paper.

U Martin: Contribution to ethics application and reporting, Recruited patients, Organised antiseptics and allocation, Sample collection, Data collection and analysis, Commented on paper.

E Gardiner: Statistical analysis, Commented on paper.

G McLorinan: Recruited patients, Performed surgeries, Sample collection, Commented on paper.

N Eames: Study design and execution, Recruited patients, Performed surgeries, Sample collection, Commented on paper. 


\section{Abstract}

\section{Aims}

To determine if sequential application of povidone iodine-alcohol (PVI) followed by chlorhexidine gluconate-alcohol (CHG) would reduce surgical wound contamination to a greater extent than PVI applied twice in spinal surgery patients.

\section{Patients and Methods}

A single-centre, interventional, two arm, parallel group randomised controlled trial of 407 patients attending hospital for elective spinal surgery was conducted.

For 203 patients, pre-surgical skin disinfection was by application of PVI (10\% [w/w ( $1 \% \mathrm{w} / \mathrm{w}$ available iodine)] povidone iodine in $95 \%$ industrial denatured alcohol; Videne Alcoholic Tincture) twice and for 204 patients application of PVI once followed by application of $\mathrm{CHG}(2 \%$ [w/v] chlorhexadine gluconate in $70 \%[\mathrm{v} / \mathrm{v}]$ isopropyl alcohol; Chloraprep with tint). The primary outcome measure was post-skin disinfection surgical site contamination determined by aerobic and anaerobic bacterial growth from post-skin disinfection samples.

\section{Results}

The detection of viable bacteria in any one of the post-skin disinfection samples (culture-positive) was significantly lower in the group treated with both PVI and CHG than in the group treated with PVI alone: $29.1 \%(59)$ vs $41.7 \%(85), \mathrm{P}=0.009$; relative risk, $0.574 ; 95 \%$ confidence interval, 0.380 to 0.866 .

\section{Conclusions}

Skin antisepsis with sequential application of PVI and CHG more effectively reduces surgical wound contamination than PVI alone. 
Take home message:

1. Sequential skin disinfection with povidone iodine-alcohol followed by chlorhexidine gluconate alcohol is more effective at reducing bacterial surgical wound contamination than disinfection with povidone iodine alcohol twice.

2. Bacteria that contaminate surgical wounds derive from the patients' skin microbiota.

3. Men are more likely to have bacterial surgical wound contamination than women. Plain Language Summary:

The increased risk of infection after surgery due to bacteria becoming resistant to antibiotics is a global concern. The source of these infections is often bacteria that are present on the patient's normal healthy skin. We have shown that by using two different antiseptics to disinfect patient's skin (one after the other), fewer patients have bacteria in the site of surgery than if only one type of disinfectant is used. This simple change to antisepsis should help to reduce the risk of post-surgical infection, particularly in orthopaedic operations such as spinal surgery and insertion of artificial joints.

\section{Introduction}

The risk of surgical-site infection is considered to be proportional to the dose and virulence of the infective agent in the surgical wound. Implants, including prosthetic joints, heart valves, intramedullary nails and metal work used for spinal stabilisation can, however, increase the likelihood of infection with bacteria of low primary virulence which are capable of causing chronic biofilm-associated infection. ${ }^{1,2}$ The control of surgical site infection at clean operative sites is dependent on the 
combined efficacy of skin disinfection and peri-operative antibiotic prophylaxis., National Institute for Health and Care Excellence UK guidelines state that the most effective skin antiseptic before surgical incision 'remains uncertain', with either aqueous or alcohol-based povidone iodine (PVI) or chlorhexidine being suitable. ${ }^{5}$ The spread of antibiotic resistance genes amongst bacteria raises the potential for resistance to prophylactic antibiotics leading to higher rates of post-operative infection. In addition, bacteria present in the surgical wound can colonise implanted biomaterials resulting in chronic infection that may not present until months or years after the initial surgery. The incidence of these biofilm-related infections is likely underestimated due to a lack of sampling from the implanted biomaterials and a lack of recognition of the importance of Propionibacterium acnes as a pathogen in this setting. ${ }^{1,2,6}$

$\mathrm{PVI}$ and chlorhexidine gluconate (CHG)-based antiseptics are recognised as safe to use and have been recommended globally for disinfection of health care worker skin and in the pre-operative disinfection of patient skin e.g. ${ }^{4}$. The disinfectant efficacy of alcoholic and aqueous preparations of each, individually, has been compared in multiple studies. For example, in relation to prevention of overt surgical site infection, Darouiche and colleagues ${ }^{7}$ reported that $9.5 \%$ of patients disinfected with CHG vs $16 \cdot 1 \%$ of patients disinfected with aqueous PVI developed surgical site infection. Comparison of PVI-alcohol versus $\mathrm{CHG}$-alcohol skin disinfection in relation to catheter-related infections indicated that $\mathrm{CHG}$ treatment resulted in a lower incidence of infection. ${ }^{8}$ The use of $\mathrm{PVI}$ and $\mathrm{CHG}$ in combination has not, however, been examined extensively.

Both chemicals are microbicidal, but via different mechanisms; the antimicrobial activity of $\mathrm{CHG}$ is related to its interaction with membranes, whereas 
microbes are killed by the iodine molecules released from PVI which results in nonspecific nucleophilic attack of microbial components. ${ }^{9,10}$

Combined use of aqueous preparations of $\mathrm{PVI}$ and $\mathrm{CHG}$ in an ex-vivo porcine infection model indicated that the two disinfectants are compatible. ${ }^{11}$ There are a small number of studies examining the effect of the sequential use of PVI and CHG on skin disinfection that suggest that combined use is more effective. For example, a skin swab study of neurosurgery patients ${ }^{12}$ and the colonisation of central venous catheters with the sequential use of $\mathrm{CHG}$ and aqueous PVI. ${ }^{13}$ Neither of these studies, and indeed few studies of skin disinfection, investigated anaerobic culture. Culture under anaerobic conditions is essential for the optimal isolation of $P$. acnes which is a predominant member of the human skin microbiota and an emerging pathogen in relation to biofilm-associated infection. ${ }^{1,14}$

The combined use of two antiseptics, each with different microbicidal action, may therefore enhance the overall efficacy of the antisepsis. In addition, if there is resistance to one antiseptic the second antiseptic may still be effective.

We hypothesised that the sequential application of $10 \%[\mathrm{w} / \mathrm{w}(1 \% \mathrm{w} / \mathrm{w}$ available iodine)] povidone iodine (PVI) in 95\% industrial denatured alcohol followed by $2 \%[\mathrm{w} / \mathrm{v}]$ chlorhexidine gluconate $(\mathrm{CHG})$ in $70 \%[\mathrm{v} / \mathrm{v}]$ isopropyl alcohol would be more effective at preventing contamination of patient surgical wounds than two applications of PVI. We monitored the efficacy of skin disinfection objectively by total viable bacterial count of intra-operative surgical site samples of skin, muscle and wound wash, not by subjective assessment of overt surgical site infection. To determine if the contaminating bacteria were derived from the patient's skin, bacteria isolated from the surgical wound were identified by molecular analyses and compared with those isolated from the patient's skin prior to disinfection. 
This report is of the first randomised controlled trial to compare the level of surgical site wound contamination by bacteria after sequential skin disinfection by $\mathrm{PVI}$ and $\mathrm{CHG}$ with both aerobic and anaerobic bacterial culture and subsequent molecular identification of bacterial isolates.

\section{Patients and Methods}

The Trial was a single-centre, interventional, randomised controlled trial conducted at Queen's University Belfast and the Belfast Health and Social Care Trust, Northern Ireland (BHSTCNI), UK. Patients attending for elective spinal surgery were recruited at two hospitals within BHSCTNI; Musgrave Park Hospital and the Royal Victoria Hospital. The study is a Medicines and Healthcare Products Regulatory Agency (MHRA) UK approved Clinical Trial of an Investigational Medicinal Product (Reference CTA 32485/0015/001-0001). Ethical approval was obtained from the Office for Research Ethics Committees Northern Ireland, Health and Social Care Research Ethics Committee 3 (Reference number 09/NIR03/79). Queen's University Belfast and the BHSCTNI were co-sponsors of the Trial. The study is registered with the European Clinical Trials database (EudraCT 2009-016566-82) and the International Standard Randomised Controlled Trials Register (ISRCTN73863246).

Patients who were to undergo elective spinal surgery with the two study surgeons were invited to participate. Patients were excluded who: were $<18$ years old; had more than 7 days hospitalisation prior to surgery; had been inpatients in another hospital and transferred for surgery; were pregnant; had known sensitivity to the skin antiseptics; or had taken antibiotics immediately prior to surgery, other than 
surgical prophylaxis. In addition, patients with overt spinal infections suspected preoperatively or where evidence of purulence in any part of the wound was observed during surgery were excluded. Recruitment began 10/05/2010 at Musgrave Park Hospital and at the Royal Victoria Hospital 26/08/2011. Consecutive patients were enrolled from 23/05/2010 until 07/07/2014. Written informed consent was obtained for all patients recruited to the study. Prior to trial commencement, the randomisation schedule was generated by a statistician not involved in the trial or assessing outcomes, as detailed in the Supplementary Material. The trial was necessarily open label to the patient and hospital staff as the antiseptics have different colours and formulation. The Principal Investigator and University staff who analysed and recorded bacterial culture from samples were, however, masked to the treatment group.

In the control group, 10\% [w/w (1\% w/w available iodine)] PVI in 95\% industrial denatured alcohol (Videne Alcoholic Tincture, Ecolab Ltd, Leeds, UK) was applied twice. In the intervention group, PVI was applied once followed by application of $2 \%$ [w/v] CHG in $70 \%$ [v/v] isopropyl alcohol (Chloraprep with tint, Enturia Ltd, Reigate, Surrey, UK). Each individual disinfectant application was timed and lasted for a minimum of 5 minutes. The primary outcome was surgical wound contamination as determined by aerobic and anaerobic viable bacterial counts. The main secondary outcome was to determine if there was a relationship between the bacteria contaminating the surgical wounds and bacteria associated with the patient's skin.

Skin surface colonisation prior to disinfection was evaluated by wet-swabbing and post-disinfection wound contamination by removal of a skin sample, an erector spinal muscle biopsy of longissimus muscle sample and a surgical wound wash 
obtained by pouring $10 \mathrm{ml}$ of sterile normal saline into the wound with aspiration after 1 minute as detailed in the Supplementary Material. Samples were transported from the operating theatre to the laboratory in an anaerobic pouch and processed under anaerobic conditions as detailed in the Supplementary Material. Total viable counts (TVCs) were estimated after at least 7 days incubation aerobically and anaerobically. Skin and muscle samples were recorded as positive for growth if more than one bacterial colony was observed on two or more of the three replicate agar plates. The wound wash was recorded as positive if five or more colonies were observed on either the aerobic or anaerobic plate. Where there was confluence and single colonies uncountable, a minimum count of 1000 was recorded. A surgical site was defined as contaminated (culture-positive) if growth was recorded in any one of skin, muscle or wound wash samples.

Operative procedure, age, sex, antibiotic prophylaxis, surgical site shaving, timing of antiseptic applications and antibiotic administration were noted. At all times theatre staff were working in accordance with normal safety procedures relevant to the surgery. Postoperative care was provided according to the principles and standards of the participating units.

The colonisation of each Surgeon's forehead was evaluated at the trial start, middle and end by surface skin swab as detailed in the Supplementary Material.

For patients with contaminated surgical sites, for each sample (i.e. skin swab, skin sample, muscle and wound wash) up to 12 colony forming units (CFUs) were archived for molecular identification by PCR amplification and sequencing (Supplementary Material, Table S1). For rapid identification of $P$. acnes, a single reaction multiplex touchdown PCR assay was used. ${ }^{15}$ Bacteria cultured from corresponding skin swabs were also analysed. A minimum of four and up to 53 
isolates were identified to species level per patient; in total 3938 bacterial isolates were identified from 141 culture-positive patients. Staphylococcus sp were also analysed for the methicillin resistance gene, mecA.

Statistical analyses Based on the rate of surgical wound contamination of approximately $30 \%$, as indicated by a previous spinal operation study in which PVI was used as the pre-surgery skin disinfectant ${ }^{16}$, we hypothesised that disinfection with PVI followed by CHG would reduce this by $40 \%$ compared to the skin disinfection with PVI used twice. On this basis it was determined that 197 patients in each group would have $80 \%$ power to determine a statistically significant difference. This assumes a $5 \%$ significance level and a two-sided hypothesis. At the request of the main funder an Independent Data Monitoring Committee (DMC) carried out a confidential interim analysis to determine if the study should cease short of the projected target patient recruitment level or if funding should be continued. Data up to April 2013 were analysed by the DMC on $22^{\text {nd }}$ May 2013. The DMC recommended continuation of the trial to its target sample size.

Analysis of the primary outcome of the presence of viable bacteria in samples post-skin disinfection was by 2-sided Fisher's Exact Test, with calculation of risk estimates and $95 \%$ confidence interval. TVCs were compared by 2-tailed t-test for equality of means. Analyses were carried out with IBM SPSS Statistics 22.

\section{Results}

Consecutive adult patients who were to undergo elective spinal surgery were enrolled from 23/05/2010 until 07/7/2014; 204 were randomly assigned to skin disinfection with PVI used twice and 204 randomly assigned to PVI followed by $2 \%$ $\mathrm{CHG}$ (Figure 1). One patient was not included in the analysis due to laboratory 
equipment failure. The baseline patient and surgical characteristics are detailed in Table 1, the types of surgery in Table S2 and the antibiotics administered in Table S3. There was one Severe Adverse Event noted: the patient had a nerve injury which is a recognised risk of all lumbar spine surgery and was not related to the study protocol. There were no adverse skin reactions to either treatments observed.

The number of patients with viable bacteria detected either aerobically or anaerobically in any one of the post-skin disinfection samples (culture-positive) was significantly lower in the group treated with both PVI and CHG than in the group treated with $\mathrm{PVI}$ alone: $29 \cdot 1 \%$ (59) vs $41.7 \%$ (85), $\mathrm{P}=0.009$; relative risk, $0.574 ; 95 \%$ confidence interval, 0.380 to 0.866 (Table 2 ). Therefore $30 \%$ fewer patients had contaminated surgical sites with sequential PVI and CHG disinfection compared to patients disinfected with only PVI. As the number of bacteria internal to the surgical site will be relevant in the context of post-operative infection, particularly in relation to implant associated biofilm infection, internal surgical site samples of muscle and the wound wash were analysed separately from the skin sample data. The number of patients with internal surgical site contamination was significantly lower in the PVI and $\mathrm{CHG}$ group than in the group treated with PVI alone (Table 2). Sequential treatment with $\mathrm{PVI}$ and $\mathrm{CHG}$ therefore resulted in $37.1 \%$ fewer patients with bacteria internal to their surgical wounds than treatment with PVI alone. Aerobic and anaerobic growth were also compared individually and a significant reduction with the use of both PVI and CHG treatment was obtained (Table 2). For both treatments there were more patients culture-positive for anaerobic growth compared to aerobic growth; 138 vs 65 .

There was no significant difference between the treatment groups in relation to the surgeon, average age, sex, whether or not the surgical site was shaved, use 
of ioban drape, incision length, length of time of antiseptic application, the length of time between prophylactic antibiotic administration and incision or the type of antibiotic administered.

To determine if either treatment was more efficient at reducing the overall bacterial load contaminating the surgical sites, samples with higher TVCs, defined as

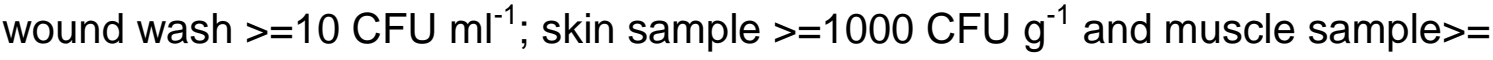
CFU $100 \mathrm{~g}^{-1}$ were analysed. There was a statistically significant reduction in the number of culture-positive patients after the sequential PVI and CHG treatment, with the exception of samples with a higher anaerobic growth which was borderline nonsignificant (Table 2). Analysis of the mean TVCs from the culture-positive samples with either aerobic or anaerobic growth revealed no statistically significant difference between the two treatment groups with respect to the mean TVC (Table S4). There were 45 patients (26 PVI group and $19 \mathrm{PVI/CHG} \mathrm{group)} \mathrm{with} 100$ or more CFUs present in the wound wash and 24 (14 PVI group and 10 PVI/CHG group) with 1000 or more CFUs. Irrespective of treatment group, more patients had internal (wound wash and muscle sample) growth anaerobically than aerobically (Figure 2).

None of the patients developed acute surgical site infections. Retrospective scrutiny of the patient's notes indicated that 10 patients had developed superficial wound infections post-operatively ( $\mathrm{PVI}$ alone $=7 ; \mathrm{PVI}$ and $\mathrm{CHG}=3$ ). Antibiotics had been prescribed in eight of these 10 cases. Only four of these patients (two from each study treatment) had culture-positive post-skin disinfection surgical samples (Table 3). The lack of serious post-surgical infection likely reflects the current efficacy of the prophylactic antibiotics.

Representative individual bacterial CFUs, in total 3938 from 141 culturepositive patient samples, were identified to species level. The patients' isolates 
belonged to the Staphylococcaceae, Propionibacteriaceae and Micrococcaceae (Table 4), with the exception of a small number of individuals from whom other species were isolated from either the skin swab or skin samples (Table S5).

S. aureus was isolated from a single patient skin swab. $M e c A^{+}$ Staphylococcus species were detected in 37 of the culture-positive patients. The isolation of facultative CoNS, obligately anaerobic S. saccharolyticus, Micrococcaceae and $P$. acnes aerobically and anaerobically from individual patient samples were compared (Figure 3). There was no statistically significant difference between the two treatments in relation to distribution of the types of bacteria isolated.

Comparison was made with bacteria identified from the skin (the pre-skin disinfection skin swab or post-skin disinfection skin sample) and the internal surgical wound samples of muscle and wound wash for each patient where culture data were available. The same species, or in the case of $P$. acnes the specific phylogroup, were identified on or in the skin and internal to the surgical wound in 96 of the 101 patients with bacteria internal to the surgical wound. This indicates that the bacteria from the patient's skin are contaminating the surgical site.

There was no significant difference between the mean estimated total viable numbers of skin surface bacteria prior to skin disinfection and the treatment group; however, men $(n=195)$ had significantly higher mean skin surface TVCs than women (Figure 4). Ninety-seven patients underwent a pre-surgery shave in theatre (90 men and 7 women) (Table 5) prior to application of the first antiseptic (Average 4 min before, maximum 19 min before).. Fifty were in the PVI treated group and 47 in the PVI and $\mathrm{CHG}$ group.

Patients whose surgical site samples were culture-positive, irrespective of treatment, had significantly higher skin surface TVCs pre-skin disinfection (Table 6 
and Figure 5). Culture-negative patients had a mean skin surface TVC of less than $10^{2} \mathrm{~cm}^{-2}$. Culture-positive patients had mean skin surface aerobic TVC of greater than $10^{2} \mathrm{~cm}^{-2}$ and greater than $10^{3} \mathrm{~cm}^{-1}$ for anaerobic growth. This indicates that patients with a higher total viable surface skin count are more likely to have viable bacteria present within the surgical wound. There was no significant difference between the treatment groups and sex 53.3\% (104) males in the PVI group vs 46.7\% (91) in the PVI and CHG group, $\mathrm{P}=0.234$ ); however, there was a significant difference in the sex distribution and culture-positive patients with more culturepositive men than women in both treatment groups (Figure 6). This was reflected by a significant difference in the skin swab TVCs between men and women (Figure 4).

The foreheads of the two surgeons who carried out the surgical operations were each swabbed on 3 separate occasions. TVCs were carried out, the predominant bacteria identified and Staphylococcus spp screened for the mecA gene (Table 7A and B). Neither of the surgeons were colonised by mecA + Staphylococcus spp; however, mecA + Staphylococcus were identified in samples from two patients who had operations on days the surgeons were sampled.

\section{Discussion}

There have been numerous studies of the efficacy of pre-surgery skin antisepsis in relation to subsequent surgical site infection in which different preparations of $\mathrm{CHG}$ and PVI were compared; however, these have been limited by the numbers of patients studied and the low incidence of surgical site infections. ${ }^{17}$ The current study was not designed to investigate surgical site infection, but to determine levels of viable bacteria at the surgical site after skin disinfection. The advantage of this approach is that there was no subjective assessment of infection and although the 
application of the antiseptics in the theatre could not be masked, the laboratory staff carrying out the bacterial culture and recording the viable bacterial counting were masked to treatment group. Also, antiseptic efficacy based on surgical site infection would have required a much larger number of participants due to the low incidence of surgical site infection. The data show that the use of PVI followed by $\mathrm{CHG}$ reduces internal surgical wound contamination, defined as bacterial culture from either the surgical site muscle sample or wound wash, by $37 \cdot 1 \%$ compared with the use of PVI alone. Therefore sequential use of $\mathrm{PVI}$ and $\mathrm{CHG}$ results in fewer patients with bacteria contaminating their surgical wounds. This significant reduction is important in the context of the potential increase of bacterial antimicrobial resistance to antibiotics used to provide surgical prophylaxis. In addition, the use of both antiseptics could potentially reduce biofilm infection of implanted medical devices, where bacteria contaminating the surgical site colonise the implanted material. A limitation of our study is that the application of $\mathrm{CHG}$ twice was not investigated. Comparison with other published studies comparing the skin disinfection efficacy of PVI and CHG application is difficult due to methodological differences and differences in the criteria used to assess the potential for wound contamination. For example, Saltzman and colleagues ${ }^{18}$ investigated culture from only dry swabs preand post- disinfection in relation to shoulder surgery and compared treatment with aqueous PVI scrub and paint, an alcoholic iodophor preparation and alcoholic CHG. The methodology used by these authors subsequently to culture from the swabs is unclear although cultures were incubated both aerobically and anaerobically. These authors, however, do report a significant reduction in the isolation of CoNS with the use of the alcoholic preparations but no significant reduction in the isolation of $P$. acnes. Langgartner and colleagues ${ }^{13}$ compared $\mathrm{CHG}(0.5 \%)$ alcohol, aqueous PVI 
$(10 \%)$ and their use in combination in relation to inserted central venous catheter insertion. Bacteria were cultured from $24.4 \%$ of the $\mathrm{CHG}$ alcohol treated, $30 \cdot 8 \%$ of the PVI treated group and $4.7 \%$ of the CHG-propanol followed by PVI treatment group, indicating increased effectiveness of the combined treatment; however, the PVI was an aqueous preparation and anaerobic culture was not investigated. Although we did not investigate whether or not the sequential use of alcoholic $\mathrm{CHG}$ and alcoholic PVI is also more effective than alcoholic $\mathrm{CHG}$ used twice, our data clearly indicates an advantage over the use of alcoholic PVI alone. It should be noted that an added advantage of the use of two different antiseptics sequentially is the potential protection against current and future antiseptic resistance.

Substantial surgical site contamination with viable bacteria post-skin disinfection also has important implications for the diagnosis of infection reliant on culture from intra-operative tissue samples and for implant-associated infection in particular. The guidelines for the intraoperative diagnosis of prosthetic joint infection by culture recommend analysis of up to six separate tissue samples, with growth of the same organism from two or more samples being considered as definitive evidence of infection. ${ }^{19}$ Our data showed that 101 patients (62 PVI group, $39 \mathrm{PVI}$ and $\mathrm{CHG}$ group) had viable bacteria within the surgical wound in numbers ranging from 10 to over 1000 CFU. The surgical wounds were only on average $7.7 \mathrm{~cm}$ in length; it is possible that larger surgical wounds, such as those for revision arthroplasty, could result in even greater surgical wound contamination. The diluent wash of retrieved implants to remove surgical site contaminating bacteria and subsequent mild ultrasound treatment to dislodge bacterial biofilm followed by microscopical and culture examination $^{20}$ may be a more reliable diagnostic for prosthetic joint infection. Our data are also important in relation to determining if there is a link between lumbar 
disc degeneration and chronic infection by $P$. acnes ${ }^{21}$ as clearly tissue removed from the surgical site can readily be contaminated by the patient's skin microbiota entering the surgical wound. Distinguishing between contamination and infection therefore has to be addressed in any studies to investigate this association.

Both treatments were less effective at reducing the contamination of the surgical site by anaerobic bacteria, which may relate to the higher numbers of anaerobic bacteria compared with aerobic bacteria pre-skin disinfection. $P$. acnes was the predominant species identified from anaerobic culture. $P$. acnes is a recognised cause of implant associated biofilm-infections ${ }^{1,22}$ and is capable of causing biofilm infection and pyogenic osteomyelitis in the absence of wear debris from the implanted material. ${ }^{23}$ The obligately anaerobic coagulase negative Staphylococcus saccharolyticus was also identified from anaerobic culture. There are few reports of $S$. saccharolyticus as a cause of infection, which may relate to lack of investigation of anaerobic coagulase negative staphylococci (CoNS). It has, however, been reported as a cause of spondylodiscitis. ${ }^{24}$

This is the first study in which multiple isolates (3938 isolates from 141 patients) of numerically dominant bacteria from the surgical sites of individual patients have been identified using molecular methods. Our data clearly indicate that patient's skin is the source of the contaminating bacteria and not the operating surgeons. By molecular identification, bacterial species and types cultured from the patient's skin and from within the surgical site could be matched in 95\% (95/101) of culture-positive patients. Bacteria cultured from the foreheads of the surgeons did not match bacteria from the surgical sites of patients from the corresponding dates. $\mathrm{MecA}^{+}$CoNS were isolated from $25 \%$ of culture-positive patients, but not from the surgeons. The clear relationship between higher pre-skin disinfection TVC and 
surgical site contamination provides further evidence for the patient's skin as the source of wound contamination. The data also revealed a clear sex difference; men had higher pre-skin disinfection TVC than women and were twice as likely to have surgical wound contamination. Men were also more likely to be shaved; only 7 of the 97 patients who were shaved were female. A number of publications indicate that men are more likely than women to have infections following medical implant related surgery (reviewed in ${ }^{25}$ ). Whether or not this relates to men having a higher bacterial load in and on their skin remains to be determined.

In conclusion, the pre-operative sequential use of PVI and $\mathrm{CHG}$ is likely to reduce the risk of post-operative biofilm associated infections arising where operations involve implanted biomaterials, in particular in relation to facultatively anaerobic coagulase negative Staphylococcus spp; however, further improvement to skin disinfection protocols needs to be investigated for patients with high $P$. acnes skin total viable counts, given its role in implant infection. Even with the improved skin disinfection of PVI and CHG, 39 (19.2\%) patients had viable bacteria within the surgical site. Therefore the diagnosis of implant-associated infection based on culture from intra-operative tissue sampling also needs to be re-addressed.

\section{Acknowledgements}

We thank all the patients who participated in the study, the independent Data Monitoring Committee and the Orthopaedic Surgery and Pharmacy staff at Musgrave Park and the Royal Victoria Hospitals, Belfast Health and Social Care Trust, for their help and support of the trial. We thank M Stevenson and the staff of the NI Clinical Trials Unit for the statistical power calculation and for generating the randomisation code. 


\section{Funding}

The R \& D Division of Health and Social Care, Public Health Agency Northern Ireland UK (RRG/3241/05 RRG 9.41) provided the main trial funding; the Mitre Charitable Trust, Musgrave Park Hospital provided funding to enable completion of the molecular analyses; CareFusion provided an unrestricted educational grant and supplied the chlorhexidine gluconate. The funders of the study had no role in study design, data collection, data analysis, data interpretation, or writing of the report. After peer-reviewed funding was agreed by the R \& D Division of Health and Social Care, Public Health Agency Northern Ireland UK, SP obtained supply of chlorhexidine gluconate for the trial free-of-charge from CareFusion.

The author or one or more of the authors have received or will receive benefits for personal or professional use from a commercial party related directly or indirectly to the subject of this article. In addition, benefits have been or will be directed to a research fund, foundation, educational institution, or other non- profit organisation with which one or more of the authors are associated.

\section{References}

1. Patrick S, McDowell A. Propionibacterium acnes: an emerging pathogen in biomaterial-associated infection. In: Moriarty TF, Zaat S, Busscher H, editors. Biomaterials Associated Infection: Immunological Aspects and Antimicrobial Strategies. 1st ed. New York: Springer; 2012. p.87-105. 
2. Kasliwal MK, Tan LA, Traynelis VC. Infection with spinal instrumentation: Review of pathogenesis, diagnosis, prevention, and management. Surg Neurol Int 2013; 4(Suppl 5): S392-403.

3. National Collaborating Centre for Women's and Children's Health. Surgical site infection prevention and treatment of surgical site infection. Clinical Guideline. Comissioned by the National Institute for Health and Clinical Excellence. London: RCOG Press; 2008.

4. Mangram AJ, Horan TC, Pearson ML, Silver LC, Jarvis WR. Guideline for prevention of surgical site infection, 1999. Hospital Infection Control Practices Advisory Committee. Infect Control Hosp Epidemiol 1999; 20: 250,78; 279-80.

5. National Institute for Health and Care Excellence. Surgical site infection. Evidence Update 43. June 2013. www.nice.org.uk; 2013.

6. Larsen LH, Lange J, Xu Y, Schonheyder HC. Optimizing culture methods for diagnosis of prosthetic joint infections: a summary of modifications and improvements reported since 1995. J Med Microbiol 2012; 61: 309-16.

7. Darouiche RO, Wall MJ,Jr, Itani KM, et al. Chlorhexidine-Alcohol versus Povidone-lodine for Surgical-Site Antisepsis. N Engl J Med 2010; 362: 18-26.

8. Mimoz O, Lucet JC, Kerforne T, et al. Skin antisepsis with chlorhexidinealcohol versus povidone iodine-alcohol, with and without skin scrubbing, for prevention of intravascular-catheter-related infection (CLEAN): an open-label, multicentre, randomised, controlled, two-by-two factorial trial. Lancet 2015; 386: 2069-77. 
9. Gilbert P, Moore LE. Cationic antiseptics: diversity of action under a common epithet. J Appl Microbiol 2005; 99: 703-15.

10. Durani P, Leaper D. Povidone-iodine: use in hand disinfection, skin preparation and antiseptic irrigation. Int Wound J 2008; 5: 376-87.

11. Anderson MJ, Horn ME, Lin YC, Parks PJ, Peterson ML. Efficacy of concurrent application of chlorhexidine gluconate and povidone iodine against six nosocomial pathogens. Am J Infect Control 2010; 38: 826-31.

12. Guzel A, Ozekinci T, Ozkan U, Celik Y, Ceviz A, Belen D. Evaluation of the skin flora after chlorhexidine and povidone-iodine preparation in neurosurgical practice. Surg Neurol 2009; 71: 207-210.

\section{Langgartner J, Linde HJ, Lehn N, Reng M, Scholmerich J, Gluck T.}

Combined skin disinfection with chlorhexidine/propanol and aqueous povidoneiodine reduces bacterial colonisation of central venous catheters. Intensive Care Med 2004; 30: 1081-8.

14. Patrick S, McDowell A. Order XII Propionibacteriales ord. nov. In: Goodfellow M, Kämpfer P, Busse H, Trujillo M, Suzuki K, Ludwig W, Whitman WB, editors. The Actinobacteria Volume 5 Part B Bergey's Manual of Systematic Bacteriology. 2nd ed. New York: Springer; 2012. p.1137-55.

15. Barnard E, Nagy I, Hunyadkurti J, Patrick S, McDowell A. Multiplex touchdown PCR for rapid typing of the opportunistic pathogen Propionibacterium acnes. J Clin Microbiol 2015; 53: 1149-55. 
16. McLorinan GC, Glenn JV, McMullan MG, Patrick S. Propionibacterium acnes wound contamination at the time of spinal surgery. Clin Orthop Relat Res 2005; 437: 67-73.

\section{Dumville JC, McFarlane E, Edwards P, Lipp A, Holmes A, Liu Z.}

Preoperative skin antiseptics for preventing surgical wound infections after clean surgery. Cochrane Database Syst Rev 2015; doi: CD003949.

18. Saltzman MD, Nuber GW, Gryzlo SM, Marecek GS, Koh JL. Efficacy of surgical preparation solutions in shoulder surgery. J Bone Joint Surg Am 2009; 91 : 1949-53.

19. Minassian AM, Osmon DR, Berendt AR. Clinical guidelines in the management of prosthetic joint infection. J Antimicrob Chemother 2014; 69 Suppl 1: i29-35.

20. McDowell A, Patrick S. Evaluation of nonculture methods for the detection of prosthetic hip biofilms. Clin Orthop Relat Res 2005; 437: 74-82.

21. Stirling A, Worthington T, Rafiq M, Lambert PA and Elliott TS. Association between sciatica and Propionibacterium acnes. Lancet 2001; 357: 2024-5.

22. Chahoud J, Kanafani Z, Kanj SS. Surgical site infections following spine surgery: eliminating the controversies in the diagnosis. Front Med 2014; $1: 7$.

23. Gahukamble AD, McDowell A, Post V, et al. Propionibacterium acnes and Staphylococcus lugdunensis cause pyogenic osteomyelitis in an intramedullary nail model in rabbits. J Clin Microbiol 2014; 52: 1595-606. 
24. Godreuil S, Jean-Pierre H, Morel J, Darbas H, Jumas-Bilak E, Banuls AL, Marchandin H. Unusual case of spondylodiscitis due to Staphylococcus saccharolyticus. Joint Bone Spine 2005; 72: 91-3.

25. Cohen B, Choi YJ, Hyman S, Furuya EY, Neidell M, Larson E. Gender differences in risk of bloodstream and surgical site infections. J Gen Intern Med 2013; 28: 1318-25. 


\begin{tabular}{|c|c|c|}
\hline & $\begin{array}{c}\text { PVI + PVI } \\
\text { Group }(n=204)\end{array}$ & $\begin{array}{c}\mathrm{PVI}+\mathrm{CHG} \text { Group } \\
(\mathrm{n}=203)\end{array}$ \\
\hline \multicolumn{3}{|l|}{ Sex } \\
\hline Female & $100(49 \%)$ & $112(55 \%)$ \\
\hline Male & $104(51 \%)$ & $91(45 \%)$ \\
\hline Age (years) & $44(36-52)$ & $47(38-58)$ \\
\hline \multicolumn{3}{|l|}{ Surgery details } \\
\hline Surgeon 1 & $121(59 \%)$ & $124(61 \%)$ \\
\hline Surgeon 2 & $83(41 \%)$ & 79 (39\%) \\
\hline Surgical site shaved & $50(25 \%)$ & $47(23 \%)$ \\
\hline Systemic antibiotics & 203 & 203 \\
\hline Incision length (cm) & $7 \cdot 7( \pm 5 \cdot 1)$ & $7 \cdot 7( \pm 4 \cdot 0)$ \\
\hline loban drape & $30(14 \cdot 7 \%)$ & $31(15 \cdot 3 \%)$ \\
\hline Implanted metal work & $36(17 \cdot 6 \%)$ & $40(19 \cdot 7 \%)$ \\
\hline \multicolumn{3}{|l|}{ Surgical site } \\
\hline Anterior cervical & $12(5 \cdot 9 \%)$ & $13(6 \cdot 4 \%)$ \\
\hline Anterior thoracic & $1(0.5 \%)$ & 0 \\
\hline Posterior cervical & $5(2 \cdot 5 \%)$ & $6(3 \cdot 0 \%)$ \\
\hline Posterior cervico-thoracic junction & $1(0.5 \%)$ & 0 \\
\hline Posterior lumbar & $179(87 \cdot 7 \%)$ & $180(88 \cdot 7 \%)$ \\
\hline Posterior thoracic & $3(1.5 \%)$ & $2(1.0 \%)$ \\
\hline Posterior thoraco-lumbar junction & $3(1.5 \%)$ & $2(1.0 \%)$ \\
\hline \multicolumn{3}{|c|}{$\begin{array}{l}\text { Data are } \mathrm{n}(\%),{ }^{1} \text { median (IQR), }{ }^{2} \text { mean (SD). PVI = povidone-iodine alcohol. } \\
\mathrm{CHG}=\text { chlorhexidine gluconate alcohol. }\end{array}$} \\
\hline
\end{tabular}


Table 2. Proportion of patients with bacterial contamination of surgical site samples after skin disinfection

\begin{tabular}{|c|c|c|c|c|c|c|c|c|}
\hline & $\begin{array}{c}\text { Positive } \\
\text { patients } \\
\text { Total } \\
(n=407)\end{array}$ & $\begin{array}{c}\text { Positive } \\
\text { patients in } \\
\text { PVI + PVI } \\
\text { Group } \\
(n=204)\end{array}$ & $\begin{array}{l}\text { Positive } \\
\text { patients in } \\
\text { PVI + CHG } \\
\text { Group } \\
(\mathrm{n}=203)\end{array}$ & $\begin{array}{c}{ }^{1} \mathrm{P} \\
\text { value }\end{array}$ & $\begin{array}{l}\text { Odds } \\
\text { ratio }\end{array}$ & $\begin{array}{c}{ }^{2} \mathrm{Cl} \\
\text { Lower }\end{array}$ & $\begin{array}{c}\mathrm{Cl} \\
\text { Upper }\end{array}$ & $\begin{array}{l}\text { Difference in } \\
\text { positive } \\
\text { patients } \\
\text { between } \\
\text { groups }\end{array}$ \\
\hline${ }^{3}$ Culture-positive & $144(35 \cdot 4 \%)$ & $85(41 \cdot 7 \%)$ & $59(29 \cdot 1 \%)$ & 0.009 & 0.574 & 0.380 & 0.866 & $26(30 \cdot 6 \%)$ \\
\hline${ }^{4}$ Internal samples culture-positive & $101(24 \cdot 8 \%)$ & $62(30 \cdot 4 \%)$ & $39(19 \cdot 2 \%)$ & 0.011 & 0.545 & 0.344 & 0.862 & $23(37 \cdot 1 \%)$ \\
\hline Aerobic culture-positive & $65(16 \cdot 0 \%)$ & $45(22 \cdot 1 \%)$ & $20(9 \cdot 9 \%)$ & 0.001 & 0.386 & $0 \cdot 219$ & 0.681 & $25(55 \cdot 6 \%)$ \\
\hline Anaerobic culture-positive & $138(33 \cdot 9 \%)$ & $79(38 \cdot 7 \%)$ & $59(29 \cdot 1 \%)$ & 0.047 & 0.648 & 0.429 & 0.980 & $20(25 \cdot 3 \%)$ \\
\hline${ }^{5}$ High Total Viable Count & $114(28 \cdot 0 \%)$ & $67(32 \cdot 8 \%)$ & $47(23 \cdot 2 \%)$ & 0.036 & 0.616 & 0.398 & 0.955 & $20(29 \cdot 8 \%)$ \\
\hline High Aerobic Total Viable Count & $33(8 \cdot 1 \%)$ & $23(11 \cdot 3 \%)$ & $10(4 \cdot 9 \%)$ & 0.028 & 0.408 & $0 \cdot 189$ & 0.880 & $13(56 \cdot 5 \%)$ \\
\hline High Anaerobic Total Viable Count & $112(27 \cdot 5 \%)$ & $65(31.9 \%)$ & $47(23 \cdot 2 \%)$ & 0.059 & 0.644 & 0.415 & $1 \cdot 000$ & $18(27 \cdot 7 \%)$ \\
\hline \multicolumn{9}{|c|}{$\begin{array}{l}{ }^{1} \mathrm{P} \text { value, Fisher's Exact Test (2-sided) } \\
{ }^{2} 95 \% \text { Confidence Interval } \\
{ }^{3} \text { Skin sample/Muscle Sample/Wound Wash } \\
{ }^{4} \text { Muscle sample/Wound wash } \\
{ }^{5} \text { Skin sample }>=1000 \mathrm{~g}^{-1} \text {, Muscle sample }>=100 \mathrm{~g}^{-1} \text {, Wound Wash }>=10 \mathrm{ml}^{-1}\end{array}$} \\
\hline
\end{tabular}




\begin{tabular}{|l|c|l|c|}
\hline \multicolumn{4}{|l|}{ Table 3. Patients with post-operative wound infection } \\
\hline $\begin{array}{l}\text { Surgical } \\
\text { disinfection } \\
\text { Treatment }\end{array}$ & $\begin{array}{c}\text { Surgical } \\
\text { site } \\
\text { samples } \\
\text { Culture- } \\
\text { positive }\end{array}$ & $\begin{array}{c}\text { Infection Notes } \\
\text { prescribed }\end{array}$ \\
\hline $\mathrm{PVI}+\mathrm{PVI}$ & $\mathrm{N}$ & developed wound infection, settled with antibiotics & $\mathrm{Y}$ \\
\hline $\mathrm{PVI}+\mathrm{PVI}$ & $\mathrm{N}$ & small ooze from wound & $\mathrm{Y}$ \\
\hline $\mathrm{PVI}+\mathrm{PVI}$ & $\mathrm{N}$ & $\begin{array}{l}\text { wound came apart, required re-admission and washout, } \\
\text { patient recovered }\end{array}$ & $\mathrm{Y}$ \\
\hline $\mathrm{PVI}+\mathrm{PVI}$ & $\mathrm{Y}$ & superficial wound infection settled & $\mathrm{Y}$ \\
\hline $\mathrm{PVI}+\mathrm{PVI}$ & $\mathrm{Y}$ & oozing wound, settled & $\mathrm{Y}$ \\
\hline $\mathrm{PVI}+\mathrm{PVI}$ & $\mathrm{N}$ & delayed wound healing with ooze & $\mathrm{Y}$ \\
\hline $\mathrm{PVI}+\mathrm{PVI}$ & $\mathrm{N}$ & ulcerated wound & $\mathrm{N}$ \\
\hline $\mathrm{PVI}+\mathrm{CHG}$ & $\mathrm{Y}$ & wound ooze & $\mathrm{N}$ \\
\hline $\mathrm{PVI}+\mathrm{CHG}$ & $\mathrm{N}$ & superficial wound infection, recovered & $\mathrm{Y}$ \\
\hline $\mathrm{PVI}+\mathrm{CHG}$ & $\mathrm{Y}$ & superficial wound infection, settled & \\
\hline $\mathrm{Y}=\mathrm{yes}, \mathrm{N}=\mathrm{no}$ & & \\
\hline
\end{tabular}




\begin{tabular}{|c|c|c|}
\hline \multirow[b]{2}{*}{ Taxonomic Family } & \multicolumn{2}{|c|}{ Bacterial Species Identified } \\
\hline & & \\
\hline & Skin $\left(\right.$ swab $^{1}$ or sample ${ }^{2}$ ) & $\begin{array}{l}\text { Wound }{ }^{2} \text { (muscle sample or } \\
\text { wash) }\end{array}$ \\
\hline Staphylococcaceae & S. aureus & \\
\hline \multirow[t]{8}{*}{$\begin{array}{l}\text { Staphylococcaceae } \\
\text { (Coagulase-negative) }\end{array}$} & $\begin{array}{l}\text { S. capitis, S. capitis subsp } \\
\text { capitis, S. capitis subsp } \\
\text { urealyticus, S. caprae, S. } \\
\text { epidermidis, S. saccharolyticus }\end{array}$ & $\begin{array}{l}\text { S. capitis, S. capitis subsp capitis, S. } \\
\text { capitis subsp urea, S. caprae, S. } \\
\text { epidermidis, S. saccharolyticus }\end{array}$ \\
\hline & $\begin{array}{l}\text { S. cohnii, S. cohnii subsp } \\
\text { urealyticus, S. equorum, S. } \\
\text { saprophyticus }\end{array}$ & S. saprophyticus \\
\hline & $\begin{array}{l}\text { S. haemolyticus, S. hominis, S. } \\
\text { hominis ss hominis, S. hominis } \\
\text { ss novobiosepticus, S. jettensis }\end{array}$ & S. hominis \\
\hline & S. lugdunensis & S. lugdunensis \\
\hline & S. lentus & \\
\hline & S. simulans & S. simulans \\
\hline & S. pasteuri, S. warneri & S. pasteuri, S. warneri \\
\hline & Staphylococcus sp. & Staphylococcus sp. \\
\hline \multirow[t]{4}{*}{ Propionibacteriaceae } & $\begin{array}{l}\text { Propionibacterium acnes } \\
\text { Type } I A_{1}, I A_{2}, I B, I C, I I, I I I\end{array}$ & $\begin{array}{l}\text { Propionibacterium acnes } \\
\text { Type } I A_{1}, I A_{2}, I B, I C, I I, I I I\end{array}$ \\
\hline & P. avidum & \\
\hline & P. granulosum & P. granulosum \\
\hline & Propionibacterium sp & Propionibacterium sp \\
\hline Micrococcaceae & $\begin{array}{l}\text { Micrococcus luteus, } \\
\text { Micrococcus yunnanensis, } \\
\text { Kocuria rhizophila, Kocuria sp }\end{array}$ & $\begin{array}{l}\text { Micrococcus luteus, Micrococcus } \\
\text { yunnanensis }\end{array}$ \\
\hline
\end{tabular}




\begin{tabular}{|c|c|c|c|c|c|c|}
\hline Skin Swab & Group & $\mathrm{N}$ & $\begin{array}{c}\text { TVC } \\
\left(\log _{10} \text { CFUs } \mathrm{cm}^{-1}\right) \\
\text { Mean }\end{array}$ & $\begin{array}{c}\text { Std. } \\
\text { Deviation }\end{array}$ & $\begin{array}{l}\text { Std. Error } \\
\text { Mean }\end{array}$ & $\begin{array}{c}\text { 2-tailed t-test for } \\
\text { Equality of } \\
\text { Means } \\
\text { P }(0.05)\end{array}$ \\
\hline \multirow[t]{2}{*}{ Aerobic } & $P V I+P V I$ & 203 & 1.66 & 1.42 & 0.10 & \multirow{2}{*}{0.466} \\
\hline & $P V I+C H G$ & 203 & 1.56 & $1 \cdot 28$ & 0.09 & \\
\hline \multirow[t]{2}{*}{ Anaerobic } & $P V I+P V I$ & 204 & $2 \cdot 40$ & 1.65 & $0 \cdot 12$ & \multirow{2}{*}{0.336} \\
\hline & $\mathrm{PVI}+\mathrm{CHG}$ & 203 & $2 \cdot 25$ & 1.42 & 0.10 & \\
\hline \multirow[t]{2}{*}{ Aerobic } & Not shaved & 310 & 1.55 & $1 \cdot 31$ & 0.07 & \multirow{2}{*}{0.083} \\
\hline & Shaved & 96 & 1.82 & 1.48 & 0.15 & \\
\hline \multirow[t]{2}{*}{ Anaerobic } & Not shaved & 310 & $2 \cdot 21$ & 1.49 & 0.08 & \multirow{2}{*}{0.006} \\
\hline & Shaved & 97 & $2 \cdot 70$ & 1.62 & 0.16 & \\
\hline
\end{tabular}




\begin{tabular}{|c|c|c|c|c|c|c|c|}
\hline $\begin{array}{c}\text { Treatment } \\
\text { Group }\end{array}$ & Skin Swab & ${ }^{1}$ Culture & $\mathrm{N}$ & $\begin{array}{c}\text { TVC } \\
\left(\log _{10} \text { CFUs } \mathrm{cm}^{-2}\right) \\
\text { Mean }\end{array}$ & $\begin{array}{c}\text { Std. } \\
\text { Deviation }\end{array}$ & $\begin{array}{l}\text { Std. Error } \\
\text { Mean }\end{array}$ & $\begin{array}{l}\text { 2-tailed t-test for } \\
\text { Equality of Means } \\
\text { P }(0.05)\end{array}$ \\
\hline \multirow{4}{*}{$P V I+P V I$} & \multirow{2}{*}{ Aerobic } & 2 & 119 & $1 \cdot 19$ & $1 \cdot 14$ & $0 \cdot 10$ & \multirow{2}{*}{$<0.001$} \\
\hline & & + & 84 & $2 \cdot 33$ & 1.52 & $0 \cdot 17$ & \\
\hline & \multirow[t]{2}{*}{ Anaerobic } & - & 119 & $1 \cdot 60$ & 1.29 & $0 \cdot 12$ & \multirow{2}{*}{$<0.001$} \\
\hline & & + & 85 & 3.52 & 1.44 & $0 \cdot 16$ & \\
\hline \multirow[t]{5}{*}{$\mathrm{PVI}+\mathrm{CHG}$} & \multirow[t]{2}{*}{ Aerobic } & - & 144 & $1 \cdot 32$ & $1 \cdot 12$ & 0.09 & \multirow{2}{*}{$<0.001$} \\
\hline & & + & 59 & $2 \cdot 16$ & 1.45 & 0.19 & \\
\hline & \multirow[t]{2}{*}{ Anaerobic } & - & 144 & $1 \cdot 75$ & $1 \cdot 17$ & $0 \cdot 10$ & \multirow{2}{*}{$<0.001$} \\
\hline & & + & 59 & 3.49 & $1 \cdot 18$ & $0 \cdot 15$ & \\
\hline & & $\begin{array}{l}{ }^{3} \text { Internal } \\
\text { culture }\end{array}$ & & & & & \\
\hline \multirow[t]{4}{*}{$P V I+P V I$} & \multirow[t]{2}{*}{ Aerobic } & - & 142 & $1 \cdot 32$ & 1.24 & $0 \cdot 10$ & \multirow{2}{*}{$<0.001$} \\
\hline & & + & 61 & 2.44 & 1.53 & 0.20 & \\
\hline & \multirow[t]{2}{*}{ Anaerobic } & - & 142 & 1.87 & 1.44 & $0 \cdot 12$ & \multirow{2}{*}{$<0.001$} \\
\hline & & + & 62 & $3 \cdot 62$ & 1.43 & $0 \cdot 18$ & \\
\hline \multirow[t]{4}{*}{$P V I+C H G$} & \multirow[t]{2}{*}{ Aerobic } & - & 164 & 1.41 & $1 \cdot 19$ & 0.09 & \multirow{2}{*}{$<0.001$} \\
\hline & & + & 39 & $2 \cdot 21$ & 1.47 & 0.24 & \\
\hline & \multirow[t]{2}{*}{ Anaerobic } & - & 164 & 1.97 & 1.29 & $0 \cdot 10$ & \multirow{2}{*}{$<0.001$} \\
\hline & & + & 39 & 3.46 & 1.30 & 0.21 & \\
\hline
\end{tabular}




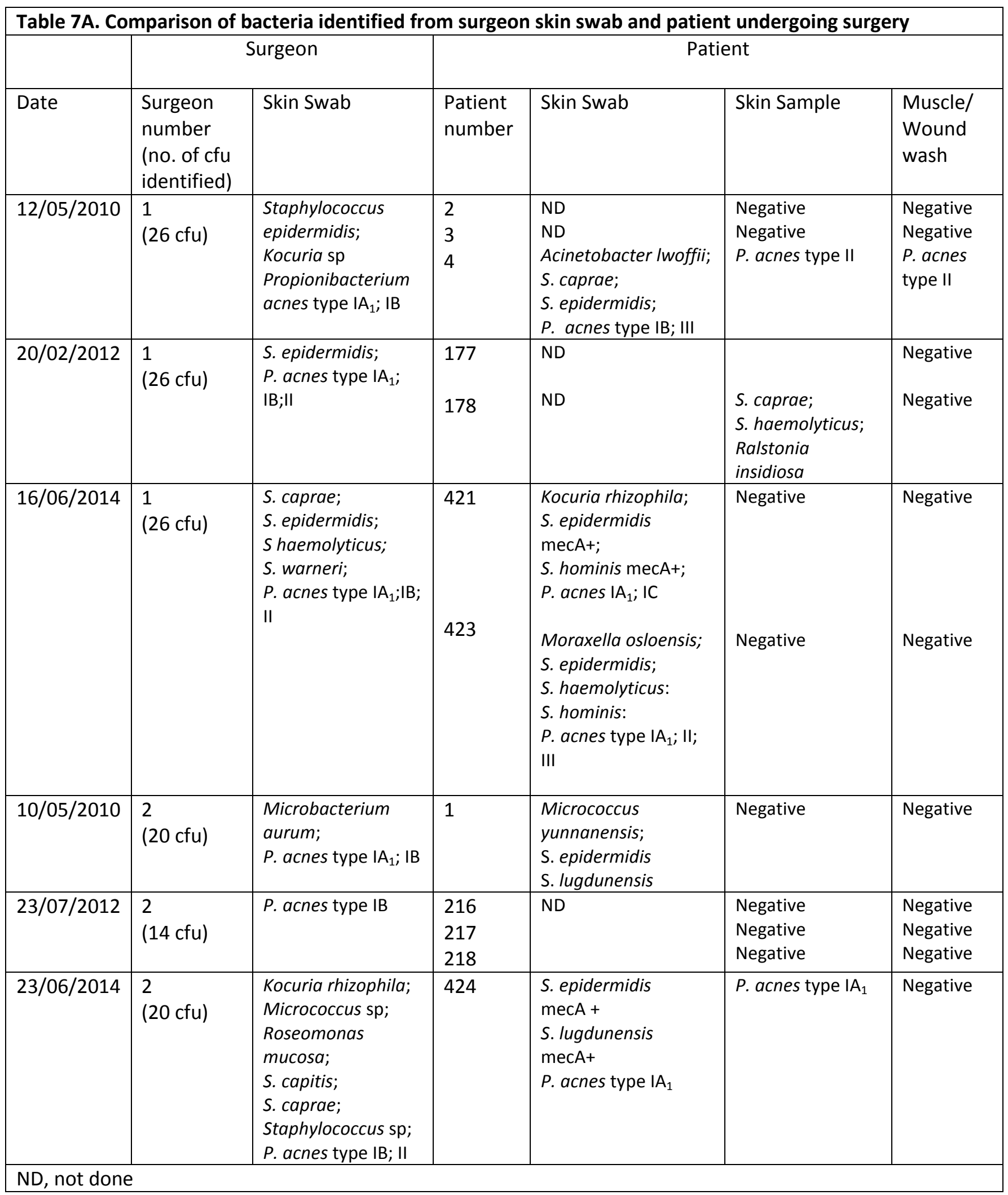




\begin{tabular}{|l|l|l|l|}
\hline \multicolumn{4}{|l|}{ Table 7B. Surgeon skin swab TVCs } \\
\hline Date & Surgeon & $\begin{array}{l}\text { Aerobic } \\
\text { CFUs cm }\end{array}$ & $\begin{array}{l}\text { Anaerobic } \\
\text { CFUs cm }\end{array}$ \\
\hline $12 / 05 / 2010$ & 1 & $4.00 \mathrm{E}+03$ & $1.13 \mathrm{E}+03$ \\
\hline $20 / 02 / 2012$ & 1 & $3.50 \mathrm{E}+02$ & $5.90 \mathrm{E}+04$ \\
\hline $16 / 06 / 2014$ & 1 & $3.30 \mathrm{E}+02$ & $2.20 \mathrm{E}+03$ \\
\hline $10 / 05 / 2010$ & 2 & $7.20 \mathrm{E}+04$ & $9.90 \mathrm{E}+03$ \\
\hline $23 / 07 / 2012$ & 2 & $9.00 \mathrm{E}+01$ & $6.40 \mathrm{E}+04$ \\
\hline $23 / 06 / 2014$ & 2 & $2.50 \mathrm{E}+02$ & $3.20 \mathrm{E}+03$ \\
\hline
\end{tabular}


30 Refused to participate

12 Excluded

1 Sensitivity to skin antiseptic

3 Antibiotic treatment

2 Patient already participated

3 Patient in hospital for $>7$ days prior to surgery

1 Infection

2 Not attending for spinal surgery

4 Patient did not attend

28 Laboratory unable to process samples

75 Surgery cancelled

64 by surgical staff

11 by patient
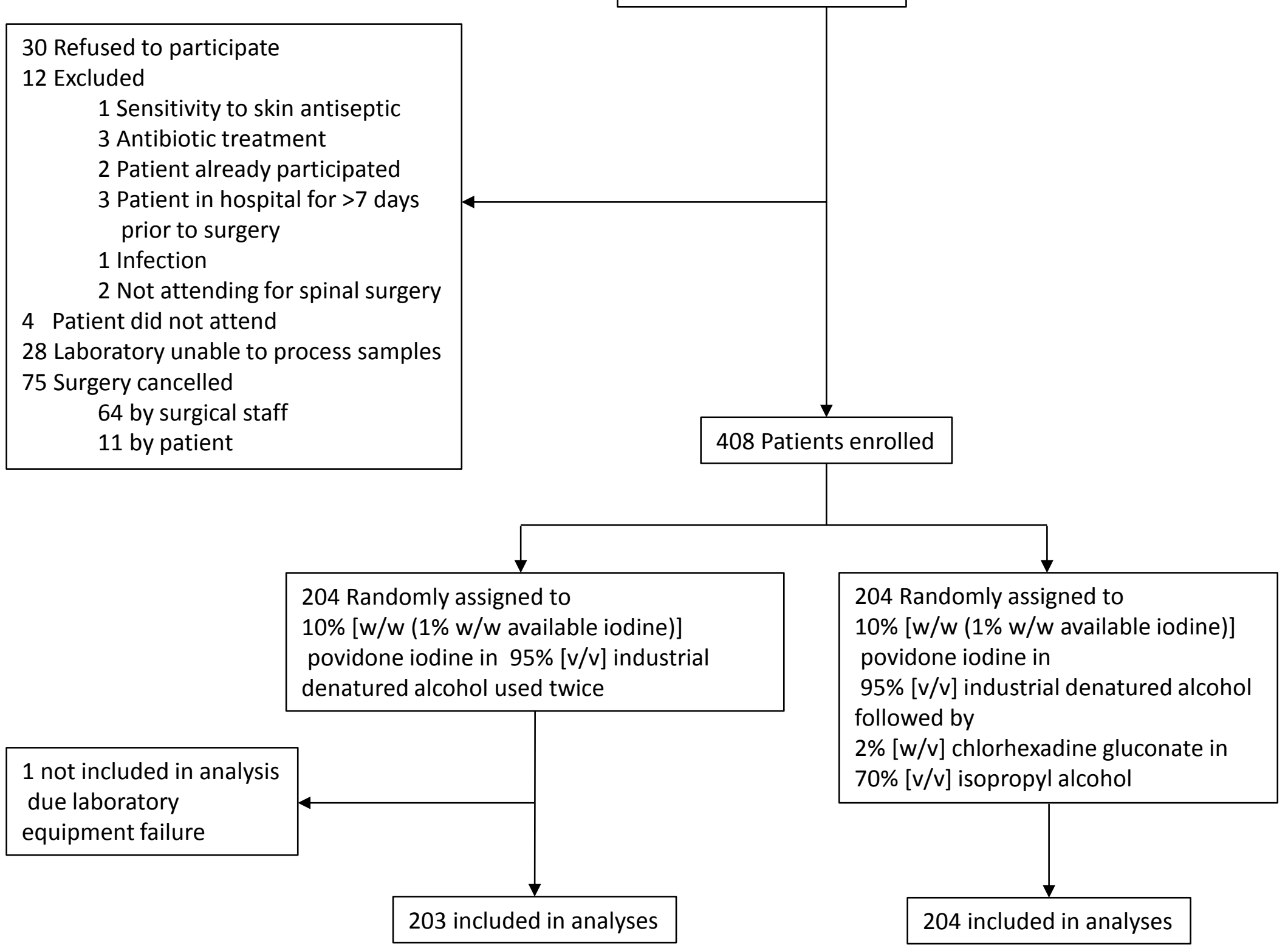

\section{Figure 1: Trial profile}




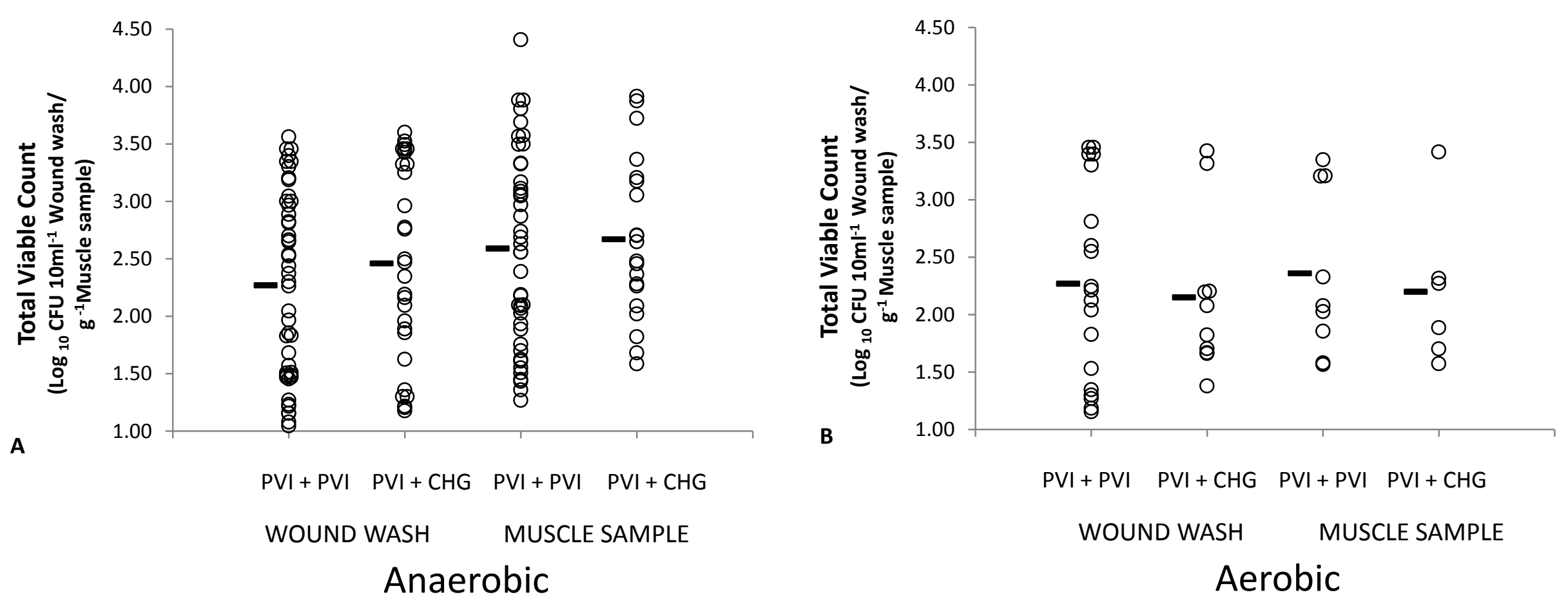

Figure 2: Total viable counts for muscle sample and wound wash for anaerobic (A) and aerobic growth (B) for each treatment group. Bar = mean. No statistical significance between the means of the two treatment groups by 2-tailed t-test for equality of means. (Appendix Table S4).

$\mathrm{PVI}=$ povidone iodine-alcohol. $\mathrm{CHG}=$ chlorhexidine gluconate-alcohol. 


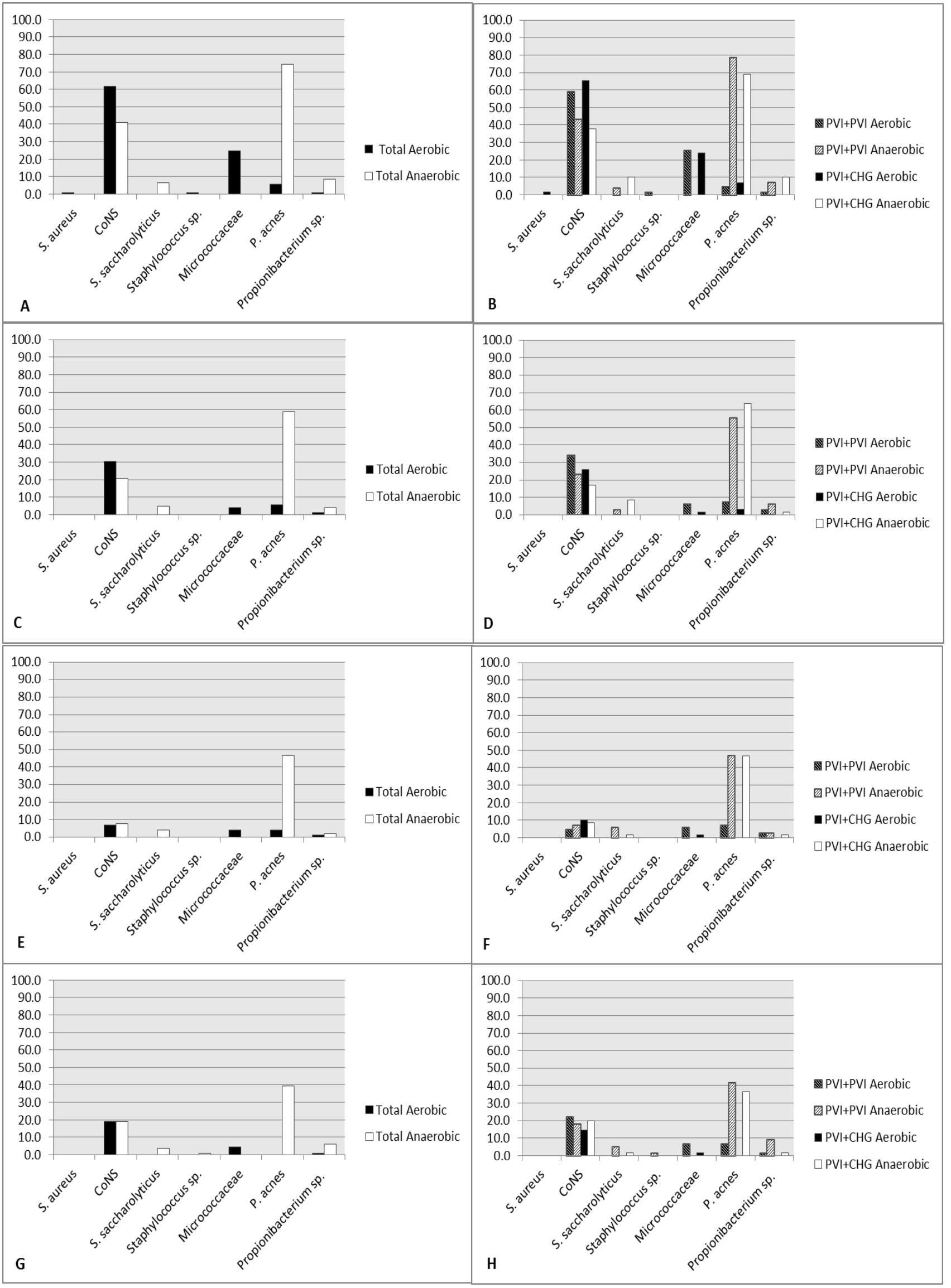


Figure 3: Frequency (\%) of different types of bacteria isolated under aerobic and anaerobic conditions from skin swab $(A, B)$, skin sample $(C, D)$, muscle sample $(E, F)$ and wound wash $(G, H)$, as a proportion of the total isolates identified for each sample $(A, C, E, G)$ and for each treatment $(B, D, F, H)$.

CoNS= coagulase negative Staphylococcus spp, except for $S$. saccharolyticus. $\mathrm{PVI}=$ povidone iodine-alcohol $\mathrm{CHG}=$ chlorhexidine gluconate alcohol 


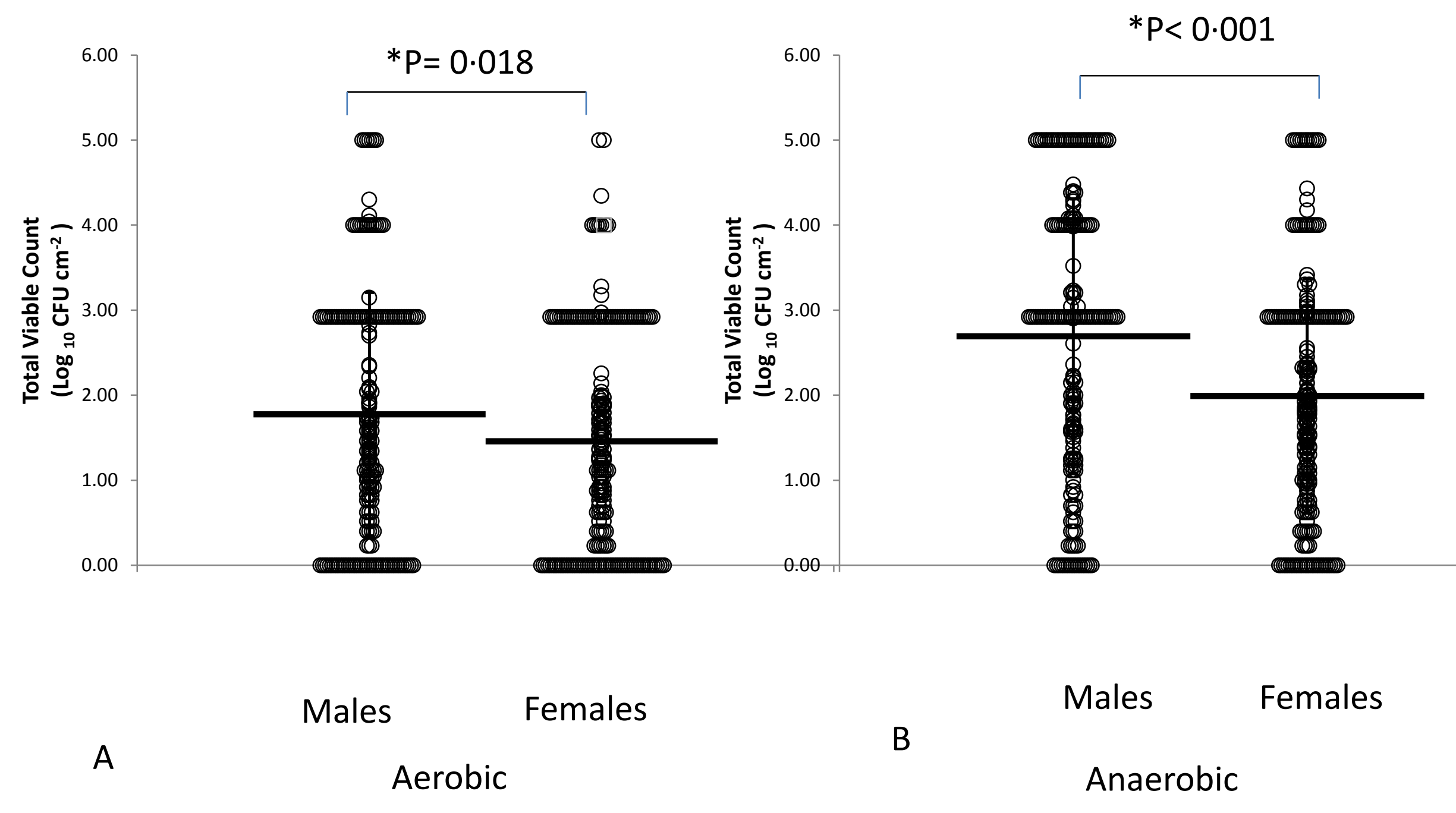

Figure 4: Comparison of skin swab aerobic and anaerobic total viable counts for males and females.

Bar=mean. ${ }^{*}=$ Statistically significant by 2 -tailed t-test for equality of means $\mathrm{P}(0 \cdot 05)$. 


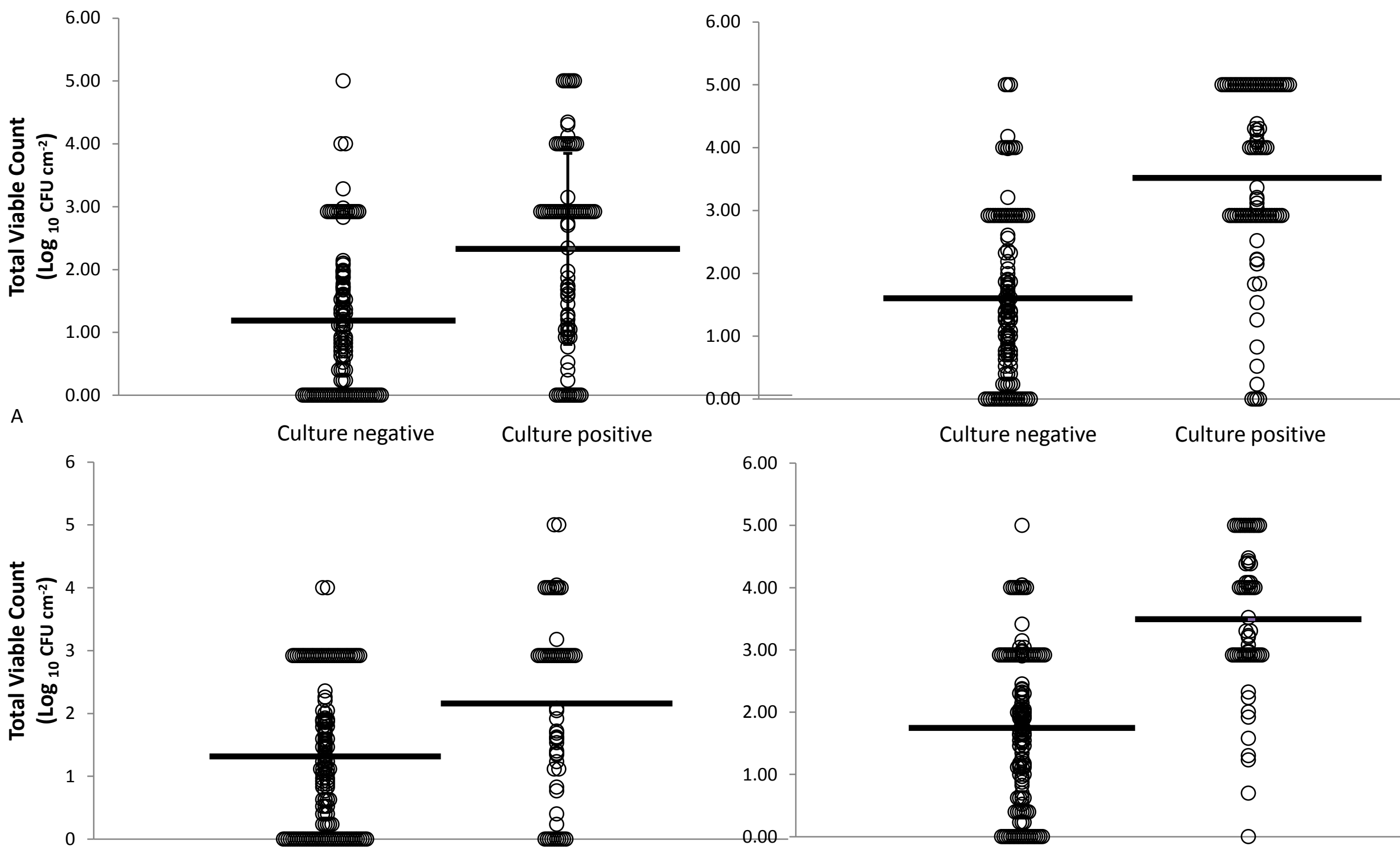

C

\section{Culture negative Culture positive}

\section{Aerobic}

Figure 5: Comparison of pre-skin disinfection skin swab aerobic and anaerobic total viable counts (TVCs) for post-skin disinfection surgical sample culture positive and negative patients. Aerobic TVCs $(A, C)$, anaerobic TVCs $(B, D)$. Povidone iodine-alcohol twice treatment $(A, B)$, Povidone iodine-alcohol followed by chlorhexidine gluconate treatment $(C, D)$. Bar=mean. ${ }^{*}=$ Statistically significant by 2 -tailed $t$-test for equality of means $\mathrm{P}(0.05)$. 


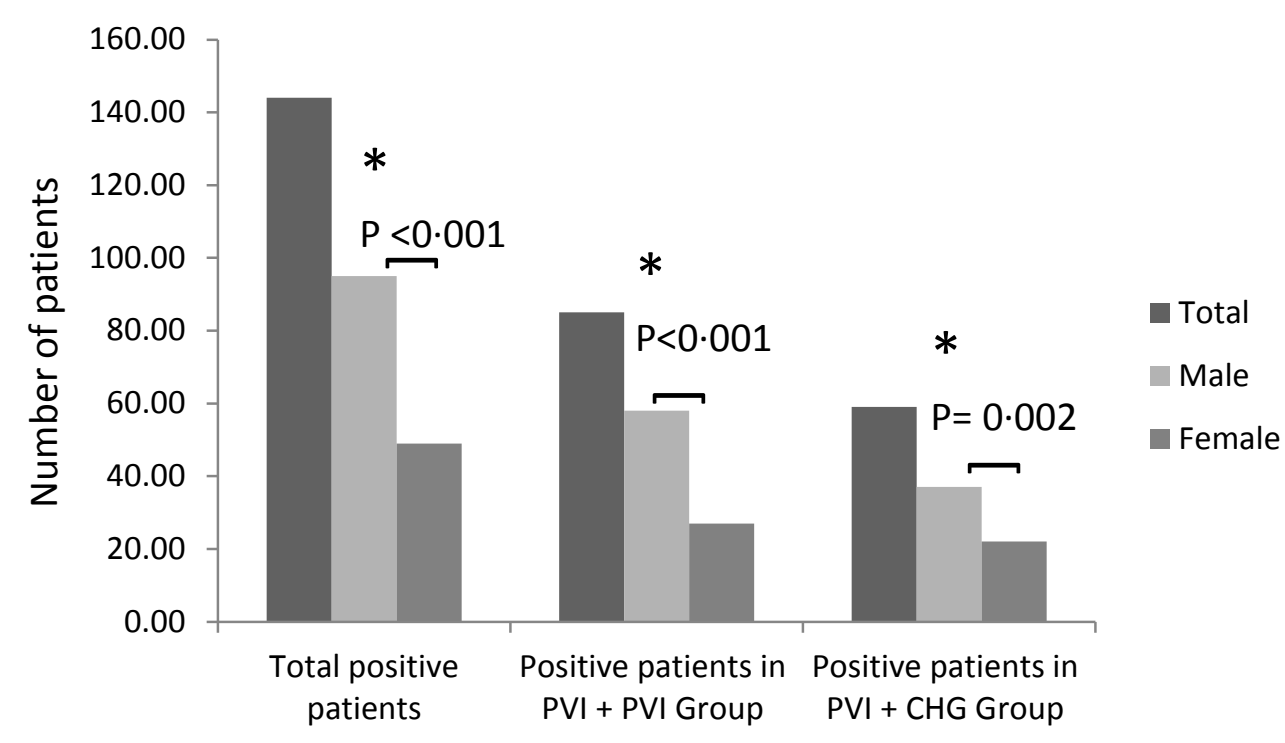

Figure 6: Comparison of the number of males and females with culture positive post-skin disinfection surgical samples. ${ }^{*}=$ statistically significant by Fisher's exact test (2-sided) $\mathrm{P}(0 \cdot 05)$.

$\mathrm{PVI}=$ povidone iodine-alcohol. $\mathrm{CHG}=$ chlorhexidine gluconate-alcohol. 


\section{Supplementary on-line material}

\section{Methods}

Randomisation and masking: Prior to trial commencement, the randomisation schedule in 500 sealed individually numbered (1-500) opaque envelopes, was generated by a statistician who was not involved in the trial or assessing outcomes. Patient recruitment began on 10/05/2010 at Musgrave Park Hospital. Recruitment at the Royal Victoria Hospital began on 26/08/2011. A unique anonymous identifier number code was assigned for each patient. Patients were enrolled at the hospital sites by a Research Nurse or assistant not involved in determining bacterial culture from samples. In advance of the patient's operation day, the randomisation envelope was opened on the hospital site in numerical order and patients were allocated to one of the two treatment groups. The Surgeon then completed a trial specific prescription form which was presented to the Hospital Pharmacy. On the day of the patient's operation, the clinical trial antiseptics were transported from the hospital Pharmacy to the Scrub Nurse in Surgical Theatre. The trial was necessarily open label to the patient and hospital staff as the antiseptics have different colours and formulation. The Principal Investigator and staff at the University who analysed and recorded bacterial culture from samples were, however, masked to the treatment group.

Surgical procedures: Skin surface colonisation prior to disinfection was evaluated by wet-swabbing. The site of surgical incision was marked along with a $5 \times 2 \mathrm{~cm}$ sampling area on the patient's skin covering where the surgical incision was to be made. The tip of a sterile sample swab (TSC Ltd., Lancashire, UK) was soaked in sterile swab tip solution (STS; 0.075M phosphate buffer, $\mathrm{pH} 7.0$, containing $0.1 \%$ 
$[\mathrm{v} / \mathrm{v}]$ Triton $\mathrm{X}-100)$ for $5 \mathrm{sec}$ before being evenly rubbed with slight pressure over the marked sampling area for 1 min to remove any surface bacteria.

After the swab had been taken the disinfectants were applied. Each individual application was timed and lasted for a minimum of 5 minutes. If required, x-rays were taken between the two applications. Sterile drapes were then applied and the incision was made. The extent of surgical site contamination after skin disinfection was evaluated by processing three samples: a) a skin sample of approximately $2 \mathrm{~mm}^{3}$ was taken from the incision site and transferred to a sterile container by the Surgeon, b) an erector spinal muscle biopsy of longissimus muscle sample of approximately $2 \mathrm{~mm}^{3}$ was removed and handled as above and c) a surgical wound wash. The latter was obtained by pouring $10 \mathrm{ml}$ of sterile normal saline into the wound immediately following removal of the muscle sample. After $1 \mathrm{~min}$ the saline wound wash was aspirated using a sterile syringe and transferred to a sterile container. Operative procedure, age, sex and antibiotic prophylaxis were noted for each patient. Shaving of the patient's surgical site before antiseptic application was noted. Times between antiseptic applications and before removal of the skin sample collection were recorded. The antibiotics and time of administration was noted. At all times theatre staff were working in accordance with normal safety procedures relevant to the surgical procedure. Postoperative care was provided according to the principles and standards of the participating units.

The colonisation of each Surgeon's forehead was evaluated at the trial start, middle and end by surface skin swab. Once the Surgeon had completed the surgical scrub, gown and glove procedure and moved beside the patient ready to begin the operation, a $5 \times 2 \mathrm{~cm}$ sampling area on the forehead visible below the surgeon's cap was marked out and swabbed in the same manner as for the patient skin. 
Sample processing: When all the samples were available in the operating theatre, the sample containers were placed into an anaerobic pouch with an AnaeroGen anaerobic atmosphere gas generation system sachet (AGS, Oxoid Ltd., Hampshire, England), excess air expelled and the anaerobic bag firmly sealed. The lids of the tissue specimen containers were slightly loosened prior to placing in the anaerobic pouch to allow anaerobic gas entry. The anaerobic bag was then placed in a disinfected jar and the lid sealed for safe transport to the laboratory. In the laboratory, samples were placed in an anaerobic workstation (Don Whitley MACS MG1000 Anaerobic Workstation, Don Whitley Scientific Ltd., Shipley, UK) interchange and once an anaerobic atmosphere was attained, transferred to the workstation (Gas atmosphere: $80 \% \mathrm{~N} 2,10 \% \mathrm{CO} 2$, and 10\% H2) for processing. To minimise areal contamination within the anaerobic workstation, the gas atmosphere was continuously pumped through a solution of glutaraldehyde $(2 \% \mathrm{v} / \mathrm{v})$ and surgical gloves worn throughout processing. The following agar media were used: prepoured fastidious anaerobic horse blood agar (BA; Fannin LIP Diagnostic Services, Galway, Ireland) and mannitol salt agar (MSA; Fannin LIP Diagnostic Services, Galway, Ireland) and in-house prepared tryptone yeast extract agar plates containing $6 \mathrm{mg} / \mathrm{ml}$ furazolidone (Propionibacterium acnes selective agar; PSA). Sterile prereduced Quarter Strength Ringer's Solution (rQSRS) containing cysteine $(0.05 \%$ $[\mathrm{w} / \mathrm{v}])$ as a reducing agent was used as a diluent. Agar plates, diluent and containers were pre-incubated for a minimum period of 48 hours within the anaerobic workstation prior to use to ensure anaerobic conditions. All agar plates were also pre-incubated to ensure sterility and the ability of agar plates to support bacterial growth was quality controlled by inoculation of selected plates with $P$. acnes NCTC 
737 (BA and PSA), Staphylococcus aureus NCTC8530 and S. epidermidis NCTC 11047 (BA and MSA).

Total viable counts (TVCs) were estimated for the skin swab by two 10 -fold dilutions. The swab tip was cut and placed in QSRS $(1 \mathrm{ml})$, vortexed and diluted. Replicate 20 microlitre drops of undiluted (6 drops) and diluted samples (5 drops each) were applied to duplicate BA plates and each set incubated either in the anaerobic workstation or aerobically at $37^{\circ} \mathrm{C}$.

TVCs for the skin and muscle samples were estimated as follows: with the lid tightened, the sample jar containing the skin sample was removed from the anaerobic workstation and weighed. The container was then placed back into the workstation and the skin sample removed using sterile forceps and finely cut with sterile scissors in a sterile plastic petri dish. Sterile forceps were used to place the skin sampling into a sterile plastic $7 \mathrm{ml}$ container containing ceramic beads (Precellys Hard Tissue Homogenizing Tubes, Stretton Scientific, Derbyshire, UK) and $6 \mathrm{ml}$ rQSRS. The cap was securely tightened and the container vortexed for 1 min. With the exception of 11 patients ( $6 \mathrm{PVI}$ treated and $5 \mathrm{PVI}+\mathrm{CHG}$ treated) the samples were ultrasound treated to dislodge follicular biofilm as follows: with the lid tightly screwed down, the container was removed from the cabinet and placed in an ultrasound bath (Decon F5200b, D\&H Ltd., Belfast, UK) pre-disinfected with 70\% (v/v) IDA and air dried, and to which sterile distilled water had been added. The container was sonicated for 5 min @ $50 \mathrm{kHz}$. The container was transferred back into the anaerobic workstation and $0.5 \mathrm{ml}$ of suspension was spread onto each of six BA plates, three PSA plates and three MSA plates using sterile plastic disposable spreaders. After drying, each set was incubated either in the anaerobic workstation 
$(3 \times \mathrm{BA}$ and $3 \times \mathrm{PSA})$ or aerobically $(3 \times \mathrm{BA}$ and $3 \times \mathrm{MSA})$ at $370 \mathrm{C}$. All plates were incubated for 7 days.

The muscle sample was weighed within the container as for the skin sample and inside the anaerobic workstation transferred to a sterile glass universal bottle containing $10 \mathrm{ml}$ rQSRS, sonicated and the diluent plated as for the skin sample. Sample weights were determined by subtracting the weights of the empty containers.

The wound wash sample was poured into a sterile, graduated centrifuge tube within the anaerobic workstation, firmly closed, the volume recorded and the tube centrifuged to pellet the cells. The tube was then returned to the anaerobic cabinet and supernatant carefully aspirated to leave a volume of $1 \mathrm{ml}$ remaining. The tube was vortexed to re-suspend the pelleted cells and $0.5 \mathrm{ml}$ was spread onto two BA plates. One plate was incubated in the anaerobic workstation and the other aerobically, at $37^{\circ} \mathrm{C}$. Wound wash samples were not taken from 22 patients (10 PVI treated and $12 \mathrm{PVI}+\mathrm{CHG}$ treated) and not processed for a further 21 patients (15 $\mathrm{PVI}$ treated and $6 \mathrm{PVI}+\mathrm{CHG}$ treated) due to clotting of the sample.

TVCs were estimated after culture under aerobic and anaerobic conditions after at least 7 days incubation. The number of colony forming units (CFUs) were recorded using a colony counter with magnifying glass (Stuart®, Bibby Scientific Ltd., Staffordshire, UK) along with colony morphologies. TVCs were expressed as CFUs cm-2 for skin swab, CFUs g-1 wet weight for skin and muscle samples and CFUs ml1 of wound wash.

Skin and muscle samples were recorded as positive for growth if more than one bacterial colony was observed on two or more of the 3 replicate agar plates. The wound wash was recorded as positive if there were five or more colonies observed on either the aerobic or anaerobic plate. In instances where there was confluence 
and colonies were uncountable a minimum count of 1000 was recorded. A surgical site was defined as contaminated (culture positive) if growth was recorded in any one of skin, muscle or wound wash samples.

For patients with contaminated surgical sites, for each sample type (i.e. skin swab, skin sample, muscle and wound wash) up to 12 CFUs, representatives of the colony morphotypes were archived in microtitre trays and stored at $-80^{\circ} \mathrm{C}$ for subsequent molecular identification. For confluent TVC plates, a loop was swept across the agar surface and re-streaked to single colonies from which representative morphotypes were then archived.

Bacterial Identification: Archived cultures were sub-cultured onto BA plates to ensure purity and DNA lysates were prepared by suspending a single CFU in $200 \mu \mathrm{l}$ of ultrapure $\mathrm{H}_{2} \mathrm{O}$ in a sterile $1.5 \mathrm{ml}$ Eppendorf tube. This was vortexed for 30 secs and then placed in a microwave oven for a total of 5 mins in $30 \mathrm{sec}$ bursts. The lysate was then cooled on ice for $1 \mathrm{~min}$ before being centrifuged at $16000 \mathrm{~g}$ for 6 minutes to remove cell debris (Eppendorf 5415D Centrifuge). The supernatants were stored at $-20^{\circ} \mathrm{C}$ until PCR amplification analyses. 16S rRNA, glyceraldehyde-3phosphate dehydrogenase (gap) and mecA gene PCR fragments (Table S1) were amplified by PCR and products were run on a E-gel 48 (2\% agarose; Invitrogen) to verify the size of the PCR product. The product were then purified and sequenced by GATC Biotech AG (Sanger sequencing, SUPREMErun 96 Applied Biosystems 3730xI DNA Analyser). Raw sequences were manually trimmed and interpreted using Chromas Lite (v2.6, http://www.technelysium.com.au/chromas.html) to ensure the quality of the sequence. Trimmed sequences were queried using a Standard Nulceotide BLAST (Basic Local Alignment Seach Tool, National Centre for Biotechnology Information, https://blast.ncbi.nlm.nih.gov/Blast.cgi) and NCBI 
database was used to find the closest sequence match, by using BLASTN algorithm. After an initial screen by PCR amplification using universal 16s rRNA gene primers ${ }^{1}$ (Table S1) and sequencing, colony morphotypes that were indicative of Staphylococcus species were analysed with glyceraldehyde-3-phosphate dehydrogenase (gap) gene primers ${ }^{2}$ (Table S1) for more accurate species identification and also for the presence of $\operatorname{mec} A$ which encodes meticillin resistance. ${ }^{3}$

Colony morphotypes indicative of Propionibacterium species were analysed by a single reaction multiplex touchdown PCR assay as described previously ${ }^{20}$ for rapid identification of $P$. acnes. Isolates that were negative for $P$. acnes multiplex analyses were re- analysed using the 16s rRNA gene universal primers. Where available, a minimum of 2 and up to 22 representative colony morphotypes from individual surgical samples were identified to species level. Bacteria cultured from corresponding skin swabs were also analysed. This represents a minimum of 4 and up to 53 isolates identified per patient; in total 3938 bacterial isolates from 141 culture positive patients.

\section{References}

1. LiPuma JJ, Dulaney BJ, McMenamin JD, Whitby PW, Stull TL, Coenye T, Vandamme P. Development of rRNA-based PCR assays for identification of Burkholderia cepacia complex isolates recovered from cystic fibrosis patients. J Clin Microbiol 1999; 37(10): 3167-70.

2. Yugueros J, Temprano A, Berzal B, Sanchez M, Hernanz C, Luengo JM, Naharro G. Glyceraldehyde-3-phosphate dehydrogenase-encoding gene as a useful taxonomic tool for Staphylococcus spp. J Clin Microbiol 2000; 38(12): 4351-5.

3. Vannuffel P, Gigi J, Ezzedine H, Vandercam B, Delmee M, Wauters G, Gala JL. Specific detection of methicillin-resistant Staphylococcus species by multiplex PCR. J Clin Microbiol 1995; 33(11): 2864-7. 


\section{Supplementary on-line material}

\section{Tables}

\begin{tabular}{|l|l|l|}
\hline \multicolumn{2}{|l|}{ Table S1. PCR amplification primer sequences for bacterial identification } \\
\hline Target Gene & Forward & Reverse \\
\hline $\begin{array}{l}\text { Universal Bacterial } \\
16 \text { rRNA gene }\end{array}$ & 5'-AGTTTGATCCTGGCTCAG-3' & 5'-GGTTACCTTGTTACGACTT-3' \\
\hline $\begin{array}{l}\text { Staphylococcus sp. gap } \\
2\end{array}$ & 5'-ATGGTTTTGGTAGAATTGGTCGTTTA-3' & 5'-GACATTTCGTTATCATACCAAGCTG-3' \\
\hline mecA $^{3}$ & 5'-TGGCTATCGTGTCACAATCG-3' & 5'-CTGGAACTTGTTGAGCAGAG-3' \\
\hline
\end{tabular}

\section{References}

1. LiPuma JJ, Dulaney BJ, McMenamin JD, Whitby PW, Stull TL, Coenye T, Vandamme P.

Development of rRNA-based PCR assays for identification of Burkholderia cepacia complex isolates recovered from cystic fibrosis patients. J Clin Microbiol 1999; 37(10): 3167-70.

2. Yugueros J, Temprano A, Berzal B, Sanchez M, Hernanz C, Luengo JM, Naharro G.

Glyceraldehyde-3-phosphate dehydrogenase-encoding gene as a useful taxonomic tool for Staphylococcus spp. J Clin Microbiol 2000; 38(12): 4351-5.

3. Vannuffel P, Gigi J, Ezzedine H, Vandercam B, Delmee M, Wauters G, Gala JL. Specific detection of methicillin-resistant Staphylococcus species by multiplex PCR. J Clin Microbiol 1995; 33(11): $2864-7$. 


\begin{tabular}{|c|c|c|c|}
\hline & Total & $\begin{array}{c}\text { PVI + PVI } \\
\text { Group (n=204) }\end{array}$ & $\begin{array}{c}\text { PVI + CHG } \\
\text { Group } \\
(\mathbf{n}=203)\end{array}$ \\
\hline Anterior Cervical Corpectomy & $1(0 \cdot 2 \%)$ & 0 & $1(0.5 \%)$ \\
\hline Anterior Cervical Discectomy and Fusion & $22(5.4 \%)$ & $11(5 \cdot 4 \%)$ & $11(5 \cdot 4 \%)$ \\
\hline Anterior Cervical Discectomy and Instrumented Fusion & $1(0 \cdot 2 \%)$ & 0 & $1(0.5 \%)$ \\
\hline Anterior Lumbar Surgery & $1(0 \cdot 2 \%)$ & $1(0 \cdot 5 \%)$ & 0 \\
\hline Anterior Thoracic Surgery & $1(0 \cdot 2 \%)$ & $1(0 \cdot 5 \%)$ & 0 \\
\hline Coccygectomy & $1(0 \cdot 2 \%)$ & $1(0 \cdot 5 \%)$ & 0 \\
\hline Costoplasty & $1(0 \cdot 2 \%)$ & 0 & $1(0.5 \%)$ \\
\hline Posterior Cervical Instrumented Fusion & $9(2 \cdot 2 \%)$ & $4(2 \cdot 0 \%)$ & $5(2.5 \%)$ \\
\hline Posterior Cervical Metal Work Revision & $2(0 \cdot 5 \%)$ & $1(0 \cdot 5 \%)$ & $1(0.5 \%)$ \\
\hline Posterior Cervical/Thoracic Metal Work Removal & $1(0 \cdot 2 \%)$ & $1(0 \cdot 5 \%)$ & 0 \\
\hline Posterior Lumbar Bilateral Discectomy & $1(0 \cdot 2 \%)$ & $1(0 \cdot 5 \%)$ & 0 \\
\hline Posterior Lumbar Bilateral/Central Decompression & $36(8 \cdot 8 \%)$ & $14(6 \cdot 9 \%)$ & $22(10 \cdot 8 \%)$ \\
\hline Posterior Lumbar Discectomy & $259(63 \cdot 6 \%)$ & $136(66 \cdot 7 \%)$ & $123(60 \cdot 6 \%)$ \\
\hline Posterior Lumbar Instrumented Fusion & $50(12 \cdot 3 \%)$ & $23(11 \cdot 3 \%)$ & $27(13 \cdot 3 \%)$ \\
\hline $\begin{array}{l}\text { Posterior Lumbar Metal Work and Decompression } \\
\text { Revision }\end{array}$ & $1(0 \cdot 2 \%)$ & 0 & $1(0.5 \%)$ \\
\hline Posterior Lumbar Metal Work Removal & $4(1.0 \%)$ & $2(1.0 \%)$ & $2(1.0 \%)$ \\
\hline Posterior Lumbar Metal Work Revision & $5(1 \cdot 2 \%)$ & $1(0 \cdot 5 \%)$ & $4(2.0 \%)$ \\
\hline Posterior Lumbar Open Biopsy & $1(0 \cdot 2 \%)$ & $1(0 \cdot 5 \%)$ & 0 \\
\hline Posterior Lumbar Unilateral Decompression & $1(0 \cdot 2 \%)$ & 0 & $1(0.5 \%)$ \\
\hline Posterior Thoracic Instrumented Fusion & $4(1 \cdot 0 \%)$ & $3(1.5 \%)$ & $1(0.5 \%)$ \\
\hline Posterior Thoracic/Lumbar Instrumented Fusion & $5(1 \cdot 2 \%)$ & $3(1 \cdot 5 \%)$ & $2(1.0 \%)$ \\
\hline \multicolumn{4}{|l|}{ Data are $\mathrm{n}(\%)$} \\
\hline
\end{tabular}




\begin{tabular}{|l|r|r|r|}
\hline Table S3. Prophylactic antibiotics administered intravenously \\
\hline Cefuroxime & \multicolumn{1}{c|}{ Total } & $\begin{array}{c}\text { PVI + PVI Group } \\
(\mathbf{n = 2 0 4})\end{array}$ & $\begin{array}{c}\text { PVI + CHG Group } \\
(\mathbf{n = 2 0 3})\end{array}$ \\
\hline Erythromycin & $288(70 \cdot 8)$ & $148(72 \cdot 5)$ & $140(69 \cdot 0)$ \\
\hline Flucloxacillin & $3(0 \cdot 7)$ & 0 & $3(1 \cdot 5)$ \\
\hline Flucloxacillin/Gentamicin & $16(3 \cdot 9)$ & $8(3 \cdot 9)$ & $8(3 \cdot 9)$ \\
\hline Flucloxacillin/Gentamicin/Teicoplanin & $17(4 \cdot 2)$ & $10(4 \cdot 9)$ & $7(3 \cdot 4)$ \\
\hline None & $1(0 \cdot 2)$ & 0 & $1(0 \cdot 5)$ \\
\hline Teicoplanin & $1(0 \cdot 2)$ & $1(0 \cdot 5)$ & 0 \\
\hline Teicoplanin/Cefuroxime & $22(5 \cdot 4)$ & $8(3 \cdot 9)$ & $14(6 \cdot 9)$ \\
\hline Teicoplanin/Gentamicin & $1(0 \cdot 2)$ & $1(0 \cdot 5)$ & 0 \\
\hline Data are $\mathrm{n}(\%)$ & $58(14 \cdot 3)$ & $28(13 \cdot 7)$ & $30(14 \cdot 8)$ \\
\hline
\end{tabular}




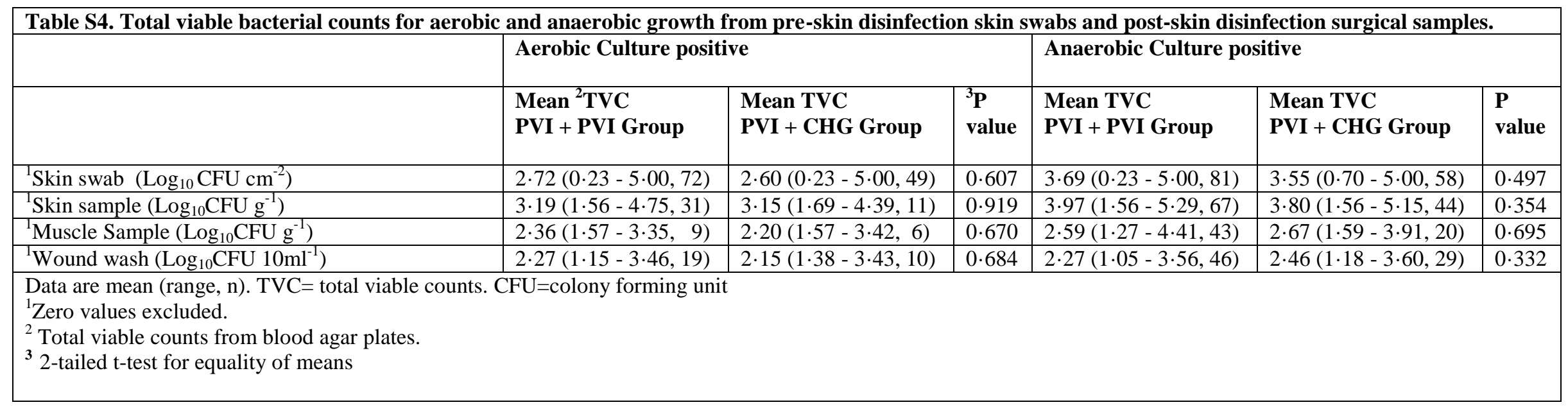




\begin{tabular}{|c|c|}
\hline $\begin{array}{l}\text { Bacteria isolated from the } \\
\text { skin of single patients }\end{array}$ & $\begin{array}{l}\text { Dermacoccus nishinomiyaensis, Janibacter sanguinis, Paracoccus yeei, } \\
\text { Enterococcus faecalis, Klebsiella oxytoca, Moraxella osloensis, Ralstonia } \\
\text { insidiosa }\end{array}$ \\
\hline $\begin{array}{l}\text { Bacteria isolated from each } \\
\text { of two patients }\end{array}$ & Acinetobacter Iwoffii, Rothia mucilaginosa \\
\hline
\end{tabular}

